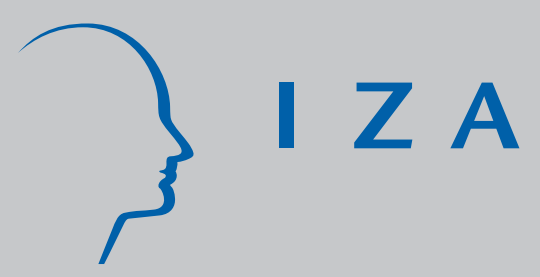

IZA DP No. 3366

International Mobility of the Highly Skilled,

Endogenous R\&D, and Public Infrastructure Investment

Volker Grossmann

David Stadelmann

February 2008 


\title{
International Mobility of the Highly Skilled, Endogenous R\&D, and Public Infrastructure Investment
}

\author{
Volker Grossmann \\ University of Fribourg, \\ CESifo and IZA \\ David Stadelmann \\ University of Fribourg
}

\author{
Discussion Paper No. 3366 \\ February 2008
}

IZA

P.O. Box 7240

53072 Bonn

Germany

Phone: +49-228-3894-0

Fax: +49-228-3894-180

E-mail: iza@iza.org

Any opinions expressed here are those of the author(s) and not those of IZA. Research published in this series may include views on policy, but the institute itself takes no institutional policy positions.

The Institute for the Study of Labor (IZA) in Bonn is a local and virtual international research center and a place of communication between science, politics and business. IZA is an independent nonprofit organization supported by Deutsche Post World Net. The center is associated with the University of Bonn and offers a stimulating research environment through its international network, workshops and conferences, data service, project support, research visits and doctoral program. IZA engages in (i) original and internationally competitive research in all fields of labor economics, (ii) development of policy concepts, and (iii) dissemination of research results and concepts to the interested public.

IZA Discussion Papers often represent preliminary work and are circulated to encourage discussion. Citation of such a paper should account for its provisional character. A revised version may be available directly from the author. 
IZA Discussion Paper No. 3366

February 2008

\section{ABSTRACT \\ International Mobility of the Highly Skilled, Endogenous R\&D, and Public Infrastructure Investment ${ }^{*}$}

This paper theoretically and empirically analyzes the interaction of emigration of highly skilled labor, an economy's income gap to potential host economies of expatriates, and optimal public infrastructure investment. In a model with endogenous education and R\&D investment decisions we show that international integration of the market for skilled labor aggravates between-country income inequality by harming those which are source economies to begin with while benefiting host economies. When brain drain increases in source economies, public infrastructure investment is optimally adjusted downward, whereas host economies increase it. Evidence from 77 countries well supports our theoretical hypotheses.

JEL Classification: F22, O30, H40

Keywords: brain drain, cross-country evidence, educational choice, public infrastructure investment, R\&D investment

Corresponding author:

Volker Grossmann

Department of Economics

University of Fribourg

$\mathrm{Bd}$. de Pérolles 90

$\mathrm{CH}-1700$ Fribourg

Switzerland

E-mail: volker.grossmann@unifr.ch

\footnotetext{
* We are grateful to Bruno S. Frey for detailed comments and suggestions on an earlier draft. We also benefited from discussion with seminar participants at the University of Zurich.
} 


\section{Introduction}

Policymakers in advanced countries are steadily concerned with attracting highly skilled workers from abroad or at least to prevent brain drain, particularly from key workers like researchers and professionals. For instance, in 2000-01, 9.2 million foreign-born professionals or technicians resided and were employed in an OECD country (OECD, 2007a). 45 percent of those work in the US, whereas Finland, Mexico, Poland and Slovak Republic experienced large net outflows. The most highly skilled are particularly mobile. Countries like Australia, Canada, the US and Switzerland are able to attract, for instance, many doctorate holders from abroad. In the US, 11.7 percent of all doctorate holders were foreign citizens and 25.7 percent of the doctorate holders (368,800 people) were foreign born in 2004; in Switzerland, the respective figures were as high as 30.1 and 41.1 percent in 2003 (Auriol, 2007). ${ }^{1}$ Many of those emigrated PhDs come from advanced EU countries, which shows that the drain of the key workforce is not exclusively a developing country phenomenon. For instance, in 2000, there were 524,922 Britons in working age (25-64) living in the US; among those, 49.2 percent had enjoyed tertiary education and 3.9 percent held a PhD (Saint-Paul, 2004). Among French, Spanish and Italian expatriates arriving at the US between 1990 and 2000 around 9 percent held a PhD (Saint-Paul, 2004). ${ }^{2}$ This shows that adverse effects from brain drain of researchers and professionals in the EU can potentially be very large, as alarmingly discussed by EU policymakers over the last years (e.g. European Commission, 2003). In view of the relatively little success of the EU to attract highly skilled labor from abroad, the European Commission proposed in October 2007 the so-called "blue card" scheme to significantly reduce immigration barriers for high-qualified workers.

A natural framework to discuss the effects of brain drain of researchers and professionals features endogenous R\&D activity of firms and endogenous educational choice of

\footnotetext{
${ }^{1}$ Figures are more moderate when we look at the broader group of the tertiary educated rather than on the most highly skilled. The number of immigrants less emigrants as percentage of all residents with tertiary attainment in 2000 was 9.1 percent in Switzerland and 3.5 percent in the US (OECD, 2007b). See also Dumont and Lemaître (2005) for an overview on immigrants and expatriates in OECD countries by level of education.

${ }^{2} \mathrm{By}$ contrast, less than one percent of working-age US citizens earned a $\mathrm{PhD}$ degree (Saint-Paul, 2004).
} 
individuals. Surprisingly, to the best of our knowledge, no such attempt yet exists in the literature.

This research develops a brain drain model which emphasizes R\&D and education decisions. It theoretically and empirically analyzes the interaction of emigration of highly skilled labor and an economy's income gap to potential host economies of expatriates. On the one hand, as common in brain drain models, high income abroad relative to the domestic economy triggers emigration. On the other hand, however, migration flows of skilled workers affect income differences across economies. The latter channel is driven by scale effects which typically arise in models with endogenous R\&D investment. In a sample of 77 countries, we find empirical evidence in favor of both channels, separately and from a structural equation model. Our analysis suggests that labor market integration (reduction of institutionally related mobility costs for the highly qualified) aggravates between-country income inequality. It raises income in economies which attracted skilled immigrants in the first place and harms economies already facing a brain drain. That is, a reduction in mobility costs accentuates both migration flows and income differentials between economies.

We next ask how the government should react to increased migration flows if it has a policy instrument at hand which can be used to raise productivity, like public infrastructure investment. Prima facie, one may suspect that countries experiencing additional brain drain should compensate for the adverse effects by spending more on productivity-enhancing measures. We show, however, that public infrastructure investment is optimally adjusted downward when exogenous shocks lead to increased outflows of high-skilled labor. ${ }^{3}$ Conversely, public investment levels should rise if the economy is more prone to immigration. Consequently, also differences in infrastructure spending across economies are accentuated after internationally integrating markets for skilled labor.

Our analysis suggests that welfare-maximization is equivalent to a minimization of brain drain in an economy with positive net emigration. Thus, reducing public infrastruc-

\footnotetext{
${ }^{3}$ The result is not due to a decrease in the tax base stemming from additional outflows; it would still hold if individuals were forced to pay taxes in their country of birth, irrespective of their residency.
} 
ture spending serves to mitigate the brain drain problem. We provide some evidence that, in line with theoretical considerations, (endogenously) increased migration outflows are accompanied by lower public investment levels.

The earlier literature has emphasized adverse effects of outward migration on the employment level and welfare of the source country (e.g. Bhagwati and Hamada, 1974). More recently, however, scholars pointed to potential brain gain effects for the source economy (e.g., Mountford, 1997; Stark, Helmenstein and Prskawetz, 1997, 1998; Beine, Docquier and Rapoport, 2001). They show that if emigration prospects of skilled workers in developing countries are uncertain due to immigration quotas in advanced countries, a higher quota (better emigration prospect) fosters incentives to acquire education. The drain effect from higher outflows may then be dominated by an increase in the skilled labor force. While not denying this possibility, our analysis does not emphasize such a mechanism. ${ }^{4}$ We also abstract from potential gains for source economies from remittances since we are interested in first-order effects of migration flows of the highly skilled on the global distribution of income earned at source.

Another strand of literature has focussed on the implications of brain drain for the tax system (e.g. Bhagwati and Wilson, 1989; Wildasin, 2000; Anderson and Konrad, 2003; Haupt and Janeba, 2004) and education subsidies (Poutvaara and Kanniainen, 2000; Andersen, 2005). Instead, we focus on the implications on public infrastructure expenditure for a given tax system. Our focus is also different but complementary to the literature on the implications of brain drain for the public education system (see e.g. Justman and Thisse, 1997, 2000; Egger, Falkinger and Grossmann, 2007). We assume that education is private but the government may affect factor productivity by other measures.

\footnotetext{
${ }^{4}$ In our model higher emigration rates are associated with a higher fraction of skilled natives too. However, an increase in the fraction of educated labor does not compensate the skill losses due to emigration. This is because there is no explicit immigration quota, albeit there exist migration costs. The migration possibilities are thus known ex ante to individuals in our framework and taken into account in the education decision. In fact, the empirical relevance of a potential brain gain mechanism is confined to poor countries with rather low levels of human capital and low emigration rates of the skilled (Beine, Docquier and Rapoport, 2001, 2008). However, as we have seen above, brain drain of researchers and professionals is not necessarily a developing country phenomenon. It is presumably not relevant for the poorest countries either, due to their lack of sufficient quality of the education system.
} 
Apart from public finance issues, our paper may be most closely related to Miyagiwa (1991), who aims to explain why countries like the US can pay high wages to skilled professionals and therefore attract the best immigrants from abroad. Miyagiwa assumes that there are increasing returns to education, which implies that the wage level of educated workers rises with the amount of skilled labor. In our model, such scale effects are endogenously derived and we provide empirical evidence for them.

The remainder of this paper is organized as follows. Section 2 presents the model. Section 3 analyzes the relationship between migration flows and income gaps without and with optimal adjustment of public infrastructure investment. Section 4 confronts the main theoretical hypotheses with empirical evidence. The last section 5 provides concluding remarks.

\section{The Model}

Consider a small economy which is populated by a unit mass of individuals, endowed with one unit of time. Each individual decides whether or not to become high-skilled, which requires $\bar{e} \in(0,1)$ units of time. ${ }^{5}$ Otherwise, it remains low-skilled. High-skilled individuals may emigrate at some cost which may differ among individuals. In order to focus on migration patterns of high skilled workers, we assume that low-skilled labor is immobile. ${ }^{6}$ Time not used for education is inelastically supplied to a perfect labor market.

An individual $i$ living at home cares exclusively about consumption level $c(i)$ of a homogenous final good. If the individual works abroad, utility is given by a discounted consumption level, $c(i) /(1+\theta(i))$; see Stark, Helmenstein and Prskawetz (1997), and Egger, Falkinger and Grossmann (2007), among others. Parameter $\theta(i)$ captures, for instance, individual costs of living in a foreign social environment, which may be affected by the treatment of foreigners by administrative bodies. It is distributed according to a

\footnotetext{
${ }^{5}$ For simplicity, individuals are homogenous with respect to required education time.

${ }^{6}$ This can be motivated by the fact that migration costs are higher for people with lower education as they are more likely to have difficulties in finding a job, learning a foreign language and integrating in the foreign society. Furthermore, institutional barriers in potential host economies may prevent migration of low-skilled workers.
} 
continuous p.d.f. $\varphi(\theta)$, with support $\Theta, \theta \geq 0$. The c.d.f. of $\theta$ is denoted by $\Phi(\theta)$. When deciding whether or not to become skilled, individuals take both migration incentives and costs into account. The net wage rate of skilled labor, affecting migration incentives as will become apparent, is exogenously given by $\bar{w}_{n e t}$.

The final good is chosen as numeraire. It is produced under perfect competition, according to the technology

$$
Y=X^{\alpha} Z^{1-\alpha}, \quad 0<\alpha<1
$$

where $X$ is a composite input consisting of $n$ intermediate goods and input $Z$ combines skilled and unskilled labor, $H_{Z}$ and $L_{Z}$, respectively, according to

$$
Z=B\left(H_{Z}\right)^{\beta}\left(L_{Z}\right)^{1-\beta}, \quad 0<\beta<1, B>0
$$

We assume that composite input $X$ is given by the CES-index

$$
X=\left[\int_{0}^{n} A(j)^{1-\alpha} x(j)^{\alpha} d j\right]^{\frac{1}{\alpha}}
$$

where $x(j)$ denotes the quantity of the intermediate input produced in sector $j \in[0, n]$ and $A(j)$ is the productivity parameter associated with that input. ${ }^{7}$

There is one firm in each intermediate goods sector. Intermediate goods producers can transform one unit of the final good into one unit of output. There is a large number of potential sectors in each economy. Entry is free but requires $f>0$ units of skilled labor for setting up a firm. ${ }^{8}$ Intermediate goods producers can improve productivity by employing high-skilled, non-production ("R\&D") labor like scientists, engineers or managers. In line with the IO literature on innovation activities (e.g., Sutton, 1998), R\&D investment costs are (endogenous) sunk costs for firms. Productivity $A(j)$ of

\footnotetext{
${ }^{7}$ According to (1)-(3), there are constant-returns to scale in final goods production.

${ }^{8}$ Assuming instead that the set up requirement is partly or exclusively in terms of low-skilled labor is inconsequential for the main results.
} 
intermediate good producer $j$ which employs $h(j)$ units of R\&D labor is given by

$$
A(j)=a(h(j))
$$

where $a(\cdot)$ is an increasing and strictly concave function; moreover, let $\lim _{h \rightarrow 0} a^{\prime}(h) \rightarrow \infty$ and $\lim _{h \rightarrow \infty} a^{\prime}(h)=0$.

According to (2), $B$ measures the total factor productivity in the production of intermediate good $Z$, referred to as "productivity" in what follows. It may be affected by public infrastructure investment, $G$, measured in terms of the final good. We assume $B=b(G)$, where $b(\cdot)$ is an increasing and strictly concave function with $b(0)>0$; moreover, we assume $\lim _{G \rightarrow 0} b^{\prime}(G) \rightarrow \infty$ and $\lim _{G \rightarrow \infty} b^{\prime}(G)=0$. Public infrastructure investment $G$ is financed by proportional wage income taxation. The tax rate is denoted by $\tau \in(0,1)$. It applies to all workers employed in the domestic economy (natives and immigrants, but not emigrants). ${ }^{9}$

We shall remark that all results would exactly remain the same if (2) and (4) were replaced by $Z=\left(H_{Z}\right)^{\beta}\left(L_{Z}\right)^{1-\beta}$ and $A(j)=B a(h(j))$, respectively; that is, instead of raising productivity in $Z$-production, an increase in $G$ would improve productivity of the R\&D process. Thus, $G$ may be interpreted as public infrastructure spending in a broad sense. One important question we wish to address is how (benevolent) national governments react to declining labor mobility costs, and possibly larger migration flows, if they have an instrument at hand which improves the economy's productivity.

\section{Equilibrium Analysis}

In this subsection we analyze the equilibrium for given public investment, $G$.

\footnotetext{
${ }^{9}$ The assumption is made for concreteness. Results would be unchanged if immigrants were not be obliged to pay taxes or if emigrants still have to pay taxes at home, as will become apparent.
} 


\subsection{R\&D decision}

We start with the decision of intermediate good firms. In view of the technology for final goods production, the inverse demand function for the latest version of intermediate input $j$ is given by

$$
p(j)=\alpha\left(\frac{A(j) Z}{x(j)}\right)^{1-\alpha}\left[\equiv \frac{\partial Y}{\partial x(j)}\right],
$$

according to (1) and (3). Recalling that each firm has marginal cost of unity, "operating profits" (sales revenue minus production costs) of firm $j$ are given by

$$
\pi(j)=\max _{p(j), x(j)}[p(j)-1] x(j) \text { s.t. }
$$

It is easy to show that prices are set according to $p(j)=1 / \alpha$ and intermediate good output levels are given by $x(j)=\alpha^{\frac{2}{1-\alpha}} A(j) Z$. Thus, resulting operating profits of a firm $j$ read $\pi(j)=\delta A(j) Z$, where $\delta \equiv(1-\alpha) \alpha^{\frac{1+\alpha}{1-\alpha}}$. Observing sunk costs and the R\&D technology (4) a firm $j$ solves

$$
\max _{h(j)} \delta Z a(h(j))-w h(j)-w f
$$

where $w$ denotes the wage rate for skilled labor. As firms are small, they take intermediate production level $Z$ as given. The first-order condition associated with optimization problem (6) implies that R\&D labor is the same for each firm $j$, i.e., $h(j)=h$. It is given by

$$
\delta Z a^{\prime}(h)=w .
$$

Free entry implies that firms enter as long as operating profits $(\pi=\delta Z a(h))$ exceed sunk costs, $w(h+f)$; thus, in equilibrium,

$$
\delta Z a(h)=w(h+f) .
$$

From $(7),(8)$ and the properties of function $a(h)$ we find that there exists a unique R\&D 
labor input per firm, $h$, which is implicitly given by

$$
a(h)-a^{\prime}(h)(h+f)=0 .
$$

$h$ only depends on the $\mathrm{R} \& \mathrm{D}$ technology and set up requirement $f$. In particular, it does neither depend on migration flows nor on public infrastructure expenditure.

\subsection{Educational choice and equilibrium wages}

Let $q$ denote the domestic wage rate for unskilled labor. If not all skilled workers are migrating, in equilibrium, $w(1-\bar{e})=q$ must hold. ${ }^{10}$ Denote the total number of (the endogenously determined) skilled and unskilled natives by $H$ and $L$, respectively, i.e., $H+L=1$, and the mass of skilled emigrants by $m$. In equilibrium with labor market clearing, we have $L_{Z}=L$ and $H_{Z}+n(h+f)=(1-\bar{e})(H-m) \cdot{ }^{11}$ Thus, $H=1-L$ implies

$$
(1-\bar{e}) L+H_{Z}+n(h+f)=(1-\bar{e})(1-m) .
$$

We next derive the equilibrium wage rate for skilled labor, $w$, and the fraction of natives choosing education, $H$, for a given amount of emigrants, $m$. For this, we use (7), (9), (10), $w(1-\bar{e})=q, H+L=1$ together with the facts that price $p_{Z}$ for the intermediate input $Z$ equals marginal productivity of the final goods sector for this input, $\partial Y / \partial Z$, and that wage rates for skilled and unskilled labor are equal the respective marginal productivity in that sector, $w=p_{Z} \partial Z / \partial H_{Z}$ and $q=p_{Z} \partial Z / \partial L_{Z}$. We thus end up with eight equations, for the eight unknowns $w, q, p_{Z}, H_{Z}, H, L, h$, and $n$. Solving the system we obtain:

Lemma 1. In equilibrium for a given amount of emigrants, $m$, the wage rate for skilled labor is given by

$$
w=\xi B a^{\prime}(h)(1-m),
$$

where $\xi \equiv \delta \beta^{\beta}(1-\beta)^{1-\beta} \frac{(1-\bar{e})^{\beta}}{1+\alpha}$ is an unessential constant, and the fraction of skilled

\footnotetext{
${ }^{10}$ Recall that individuals have identical time costs, $\bar{e}$, to become skilled.

${ }^{11}$ Recall that skilled individuals work only a fraction $(1-\bar{e})$ of their time.
} 
natives reads

$$
H=\frac{\alpha+\beta+(1-\beta) m}{1+\alpha}
$$

All proofs are relegated to the Appendix. One can also show that per capita output of the final good, $y \equiv \frac{Y}{1-m}$, is given by $y=\tilde{\xi} B a^{\prime}(h)(1-m)$, where $\tilde{\xi} \equiv \frac{(1-\bar{e}) \xi}{(1-\alpha)(1+\alpha)}$. Thus, $y$ and wage rates are proportional to each other (see (11)) and positively depend on the "scale" of the domestic labor force, $1-m ; y$ and $w$ therefore decline in the number of emigrants $m$. Such a scale effect is in line with almost all models of endogenous technical change. $^{12}$

Three further remarks are in order. First, according to (9), there is no scale effect regarding $\mathrm{R} \& \mathrm{D}$ labor input per firm and thus no scale effect regarding average productivity of intermediate goods firms. This is because larger scale, and thus larger market size, means that more firms enter the economy, in a proportional way. ${ }^{13}$ This feature of the model is consistent with recent empirical evidence provided by Laincz and Peretto (2006) in the context of vertical innovation models. ${ }^{14}$ Second, note that raising productivity $B$ has a lower effects on the wage rate $w$ the higher the number of emigrants $(m)$ is. This insight plays an important role for the policy analysis in subsection 3.4. Third, note from (12) that the number of high-skilled individuals $(H)$ is positively associated with the number of migrants, $m$. This is due to the complementarity of skilled and unskilled labor in the production of the intermediate input $Z$. Higher brain drain means that a lower amount of skilled labor is employed at home, which in turn raises the marginal productivity of skilled relative to unskilled labor and therefore fosters education incentives. However, we have $H_{m}<1$, which implies that an increase in $H$ is lower than the loss because of brain drain. ${ }^{15}$ Moreover, $H>m$ whenever $m<1$, i.e., both skilled and unskilled natives work in the considered economy.

\footnotetext{
${ }^{12}$ See Grossmann (2008) for an exception. For a comprehensive survey, see Jones (2005).

${ }^{13}$ See the proof of Lemma 1 in Appendix.

${ }^{14}$ In vertical innovation models, $R \& D$ is targeted to productivity-improvements, like in this paper. Proportionality of firm size to the size of the domestic labor force is a key feature in this class of models. See Grossmann and Steger (2007) for a discussion.

${ }^{15}$ This is different to recent models with uncertain individual prospects to migrate, like Mountford (1997) or Stark, Helmenstein and Prskawetz $(1997,1998)$. In our model, individuals know in advance their migration costs.
} 


\subsection{Migration}

We turn next to the migration decision of individuals. Let $w_{n e t} \equiv(1-\tau) w$ be the net wage rate a skilled worker earns at home (whereas $\bar{w}_{n e t}$ is earned abroad). As consumption equals after-tax wage income and is discounted by $\theta(i)$ when moving abroad, an individual $i$ emigrates if $\bar{w}_{n e t} \geq(1+\theta(i)) w_{n e t}$. This condition can be rewritten as $\theta(i) \leq \chi-1$, where $\chi \equiv \bar{w}_{n e t} / w_{\text {net }}$ is the relative after-tax wage abroad. Thus, if $\chi \geq 1$, then the number of emigrants is given by $m=\int_{0}^{\chi-1} \varphi(\theta) d \theta=\Phi(\chi-1)$. Suppose that in the case where $\chi<1$, there will be immigration of $I(\chi)$ workers, i.e., $m=-I(\chi)$. We assume that $I(\chi)$ is a decreasing function (i.e. immigration rises if the relative wage $\chi$ abroad declines) and $I(1)=0$. In sum, the number of migrants is given by

$$
m=\left\{\begin{array}{c}
\Phi(\chi-1) \text { if } \chi \geq 1 \\
-I(\chi) \text { otherwise }
\end{array}\right.
$$

Note that $m$ increases if the relative after-tax wage abroad, $\chi$, increases. Moreover, if $\chi=1$, then $m=0$.

The government budget constraint for financing public infrastructure, given tax rate $\tau$, reads $G=\tau[q L+w(1-\bar{e})(H-m)]$. Using equilibrium condition $q=w(1-\bar{e})$ and $H+L=1$, we have $\tau w=\frac{G}{(1-\bar{e})(1-m)}$. Employing the latter expression together with (11), it follows that the after-tax wage of skilled labor is given by

$$
w_{n e t}=\xi B a^{\prime}(h)(1-m)-\frac{G}{(1-\bar{e})(1-m)} \equiv W(m, B, G) .
$$

Not surprisingly, higher productivity, $B=b(G)$, makes an economy less prone to brain drain $\left(W_{B}>0\right)$, all other things being equal. This holds because equilibrium wages are increasing in productivity. However, raising $B=b(G)$ by enhancing public infrastructure investment, $G$, comes at the cost of higher tax payments. This lowers net wages $\left(W_{G}<0\right)$ and through this effect fosters emigration. Outward migration of skilled workers has two negative effects on net wage rate $w_{n e t}$ in the domestic economy, all other things equal: first, the gross wage declines due to the scale effect described in subsection 
3.2 and, second, the tax base shrinks which in turn lowers after-tax income for a given public spending level; formally $W_{m}<0 .{ }^{16}$

Let us define $\tilde{W}(m, G) \equiv W(m, b(G), G)$. According to (14) and $b^{\prime \prime}(G)<0$, for a given number of migrants, $m$, net wages are strictly concave as a function of public infrastructure investment, $G$, i.e., $\tilde{W}_{G G}<0$. (This property is important when we turn to optimal policy setting below.) Moreover, we can write the relative after-tax wage income abroad, $\chi=\bar{w}_{n e t} / w_{n e t}$, as

$$
\chi=\frac{\bar{w}_{n e t}}{\tilde{W}(m, G)} \equiv \tilde{\chi}\left(m, G, \bar{w}_{n e t}\right)
$$

As emigration has a negative effect on the net wage at home $\left(W_{m}<0\right)$, the relative wage rate abroad rises with $m\left(\tilde{\chi}_{m}>0\right)$. Thus, there exists a unique threshold level, $\underline{m}$, such that $\tilde{\chi}\left(\underline{m}, G, \bar{w}_{n e t}\right)=1$. We have $\underline{m}<0$ if and only if $\tilde{\chi}\left(0, G, \bar{w}_{n e t}\right)>1$, i.e., $\underline{m}<0$ is associated with a premium on net wages abroad in the case where there is no migration $(m=0)$. Similarly, $\underline{m}>(=) 0$ if and only if $\tilde{\chi}\left(0, G, \bar{w}_{n e t}\right)<(=) 1$. Combining (13) and (15), we obtain:

Lemma 2. (i) In an equilibrium with $m \geq \underline{m}$, the number of emigrants, $m$, is implicitly given by

$$
m=\Phi\left(\tilde{\chi}\left(m, G, \bar{w}_{n e t}\right)-1\right) \equiv M\left(m, G, \bar{w}_{n e t}\right),
$$

where $M$ is increasing in $m$; if $\varphi$ is non-decreasing, $M$ is also strictly convex as a function of $m$. (ii) In an equilibrium with $m<\underline{m}$, there is immigration $(m<0)$, where $m$ is implicitly given by $m=-I\left(\tilde{\chi}\left(m, G, \bar{w}_{n e t}\right)\right)$.

Let $\hat{m}\left(G, \bar{w}^{n e t}\right)$ denote the equilibrium number of migrants (emigrants if $\hat{m}>\underline{m}$ and immigrants if $\hat{m}<\underline{m})$. An equilibrium $\hat{m}\left(G, \bar{w}^{\text {net }}\right)$ with emigration is implicitly defined by $m=M\left(m, G, \bar{w}_{n e t}\right)$. For $m>\underline{m}$, the three panels in Fig. 1 graph possible curves of $M\left(m, G, \bar{w}_{n e t}\right)$ as a function of $m$, called $M$-curves. ${ }^{17}$ Graphically, $\hat{m}$ is determined

\footnotetext{
${ }^{16}$ If emigrants would be obliged to pay taxes in the source country, only the first effect was present. As still $W_{m}<0$ in this case, results would remain qualitatively unchanged.

${ }^{17}$ Note from (16) that the shape of the $M$-curve critically depends on the c.d.f. of mobility costs, $\Phi$,
} 
by the intersection of the $M$-curve with the 45-degree line. Panel (a) of Fig. 1 shows a situation where $\underline{m}=0$ such that there is an equilibrium without any migration, $\hat{m}\left(G, \bar{w}^{\text {net }}\right)=0$. Moreover, there is a second equilibrium with positive migration. The potential multiplicity of equilibrium arises from the fact that higher emigration lowers net wages at home (recall $W_{m}<0$ ) and thus makes emigration even more attractive. Panel (b) depicts a case where $\underline{m}<0$, the $M$-curve is $\mathcal{S}$-shaped, and for the solid line there are three equilibria with emigration. ${ }^{18}$ Panel (c) depicts a case where $\underline{m}>0$ and there are two equilibria with emigration. For $m<\underline{m}$, we have three additional equilibria with immigration.

\section{$<$ Figure 1 here $>$}

Throughout, we focus our comparative-static analysis on equilibria which are stable according to the standard notion: Consider an equilibrium with emigration, $\hat{m}>0$. Suppose that in the case where emigration would slightly decrease to $\tilde{m}<\hat{m}$, the relative net wage abroad $(\chi)$ adjusts such that $M\left(\tilde{m}, G, \bar{w}_{n e t}\right)>\tilde{m}$. Similarly, if emigration increased to $\tilde{m}>\hat{m}$, then the resulting number of migrants would fall below $\tilde{m}$. The equilibrium with $\hat{m}>0$ is thus "stable" in the sense that small perturbations lead to a tendency of equilibrium to return to its initial level. Fig. 1 reveals that this is the case if $M_{m}\left(\hat{m}, G, \bar{w}_{n e t}\right)<1$. Otherwise, if $M_{m}\left(\hat{m}, G, \bar{w}_{n e t}\right)>1$, the equilibrium is called "unstable", as slightly decreasing emigration to $\tilde{m}<\hat{m}$ would lead to less migration, $M\left(\tilde{m}, G, \bar{w}_{n e t}\right)<\tilde{m}$, and slightly increasing emigration to $\tilde{m}>\hat{m}$ would lead to higher emigration. In the case of immigration, we apply an analogous notion of stability. An equilibrium with immigration is thus stable if $-I^{\prime}(\tilde{\chi}) \tilde{\chi}_{m}<1$ holds in equilibrium.

In panel (a) of Fig. 1, there is only one stable equilibrium, which is the one where $\hat{m}\left(G, \bar{w}^{n e t}\right)=\underline{m}=0$. The equilibrium with positive emigration is unstable. If the $M$-curve is like the solid line depicted in panel (b) of Fig. 1, the equilibria with $\hat{m}_{1}$ and $\hat{m}_{3}$ are both stable whereas the equilibrium in the middle, $\hat{m}_{2}$, is unstable. In panel

\footnotetext{
which is exogenously given.

${ }^{18}$ According to Lemma $2, M_{m m} \leq 0$ requires that the p.d.f. of mobility costs must be strictly decreasing, i.e., $\varphi^{\prime}<0$, in the relevant range; otherwise, the $M$-curve is strictly convex, as in panel (a).
} 
(c), there is only one stable equilibrium with emigration, but two stable equilibria with immigration.

We next examine the effects of an increase in the foreign wage, $\bar{w}_{n e t}$, and of a decrease in mobility costs, for given public infrastructure investment. A decrease in mobility costs is defined as a shift in the c.d.f. of $\theta$, from $\Phi(\theta)$ to $\tilde{\Phi}(\theta)$, such that $\tilde{\Phi}(\theta)>\Phi(\theta)$ for all $\theta$ in the interior of support $\Theta$ (i.e., $\Phi(\theta)$ first-order stochastically dominates $\tilde{\Phi}(\theta)$ ). In words: for any given $\theta$, the share of individuals with mobility costs higher than $\theta$ increases and the share of individuals with costs lower than $\theta$ declines. Moreover, we say that the economy becomes more prone to immigration if there is a shift from $I(\chi)$ to $\tilde{I}(\chi)$ such that $I(\chi)>\tilde{I}(\chi)$ for all $\chi \in(0,1)$. The following comparative-static results hold.

Proposition 1. Assume that at least one stable equilibrium exists. ${ }^{19}$ Then for a given public investment level $G$ the following holds:

(i) Suppose $\hat{m}=\underline{m}=0$ initially. If mobility costs decline, then still $\hat{m}=0$. If $\bar{w}_{n e t}$ increases, then emigration becomes positive $(\hat{m}>0)$.

(ii) Let $\hat{m}^{\text {high }}$ be the number of emigrants in a stable equilibrium $\hat{m}\left(G, \bar{w}_{\text {net }}\right)>0$ where emigration is highest. If mobility cost decline or if $\bar{w}_{n e t}$ increases, then $\hat{m}^{\text {high }}$ increases (higher emigration) and the corresponding equilibrium net wage rate for skilled labor, $W\left(\hat{m}^{\text {high }}, B, G\right)$, declines.

(iii) Let $\hat{m}^{\text {low }}$ be the number of immigrants in a stable equilibrium $\hat{m}\left(G, \bar{w}_{\text {net }}\right)<0$ where immigration is highest. If the economy becomes more prone to immigration or if $\bar{w}_{\text {net }}$ declines, then $\hat{m}^{\text {low }}$ decreases (higher immigration) and $W\left(\hat{m}^{\text {low }}, B, G\right)$ increases.

Higher labor mobility means that for any relative wage abroad, $\chi>1$, more workers are willing to migrate. Thus, as depicted for the dotted line in panel (a) as well as for both the dotted and dashed lines in panel (b) in Fig. 1, the $M$-curve from shifts upward. As $\underline{m}$ is unchanged by definition (recall $\tilde{\chi}\left(\underline{m}, G, \bar{w}_{\text {net }}\right)=1$ ), the stable equilibrium without emigration in panel (a) is unchanged. In contrast, if the net wage rate abroad $\left(\bar{w}_{n e t}\right)$ rises, $\chi$ increases and thus the $M$-curve shifts upward also for $m=0$; in addition, $\underline{m}$

\footnotetext{
${ }^{19}$ It may be the case that a stable equilibrium exists for some c.d.f. $\Phi$ and foreign net wage $\bar{w}_{n e t}$, but fails to exist after a decrease in mobility cost or an increase in the foreign net wage rate. To avoid only mildly interesting case distinctions, we do not consider such a scenario in what follows.
} 
falls below zero. Consequently, in the new (stable) equilibrium, a positive amount of workers emigrate. This explains part (i) of Proposition 1. Now consider part (ii). For both the solid and the dotted $M$-curve in panel (b) of Fig. 1 there are two stable equilibria. After a decrease in mobility cost (dotted curve) both the lower one and the higher one are associated with higher emigration than $\hat{m}_{1}$ and $\hat{m}_{3}$, respectively. For a larger reduction in mobility costs, leading to the dashed $M$-curve, the stable lowemigration equilibrium vanishes (as does the unstable equilibrium). In any case, the highest emigration level in a stable equilibrium $\left(\hat{m}^{h i g h}\right)$ rises. Moreover, as emigration has a negative effect on wages (recall $W_{m}<0$ ), moving from one stable equilibrium to another one which is associated with a higher number of emigrants triggers a fall in the equilibrium wage rate for both skilled and unskilled labor (recall $q=(1-\bar{e}) w$ ). An increase in the net foreign wage, $\bar{w}_{n e t}$, again shifts the $M$-curve upwards and lowers $\underline{m}$. It therefore triggers higher emigration (provided the equilibrium is stable), in turn depressing wage rates at home. The opposite results hold when the economy becomes more prone to immigration which means that function $I(\chi)$ shifts. In panel (c), this is indicated by a downward shift from the solid to the dotted curve for the range $m<\underline{m}$, resulting in an increase of the (highest) number of immigrants (decrease of $\hat{m}^{\text {low }}$ ). This explains part (iii) of Proposition 1.

Proposition 1 suggests that, for given public expenditure $G$, both migration flows and wage differences among economies are accentuated if mobility costs decline. Interesting questions which arise from this result are: Should a (benevolent) government raise the level of public investment $(G)$ to increase productivity $B$ in response to lower mobility costs, for instance, in order to possibly compensate non-migrating workers for the wage decline following higher brain drain? Moreover, how does the optimal policy response depend on the direction of the accentuated migration flow? These questions are analyzed next. 


\subsection{Optimal Public Investment Policy}

If there is more than one stable equilibrium, then which one materializes depends on the beliefs of skilled workers about the migration pattern. In equilibrium, beliefs must be identical. We assume that the government anticipates these beliefs when choosing public investment policy $G$.

To analyze policy setting behavior, we first have to formulate a government objective or "welfare measure". We assume that governments exclusively care about utility of native individuals living in the domestic economy (non-migrants), given by consumption level $c(i)$. This may be the case, for instance, because non-migrants represent the median voter in the economy. Since consumption equals domestic after-tax wage income (which is the same for skilled and unskilled workers, as individuals are identical ex ante), the government aims to maximize

$$
w_{n e t}=\tilde{W}\left(\hat{m}\left(G, \bar{w}_{n e t}\right), G\right) \equiv \hat{W}\left(G, \bar{w}_{n e t}\right) .
$$

We denote the government's optimal expenditure by $\hat{G}\left(\bar{w}_{n e t}\right)\left[\equiv \arg \max _{G \geq 0} \hat{W}\left(G, \bar{w}_{n e t}\right)\right]$ and show the following.

Proposition 2. Assume that at least one stable equilibrium exists. The optimal public expenditure level, $\hat{G}$, minimizes emigration from a source economy or maximizes immigration to a host economy; that is, $\hat{m}_{G}\left(\hat{G}, \bar{w}_{\text {net }}\right)=0$ and $\hat{m}_{G G}\left(\hat{G}, \bar{w}_{\text {net }}\right)>0$ hold.

Proposition 2 highlights the adverse effects of brain drain for a source economy, or the beneficial effects of immigration for a host economy, for income and welfare of nonmigrants in the model. It shows that welfare maximization through public infrastructure investment policy is, in a source country, equivalent to minimizing brain drain. In a host economy, it is equivalent to maximizing the inflow of skilled workers. We next show in which direction the optimal infrastructure investment changes if mobility costs decline and, therefore, migration flows accentuate.

Proposition 3. Assume that at least one stable equilibrium exists. 
(i) Suppose $\hat{m}\left(\hat{G}, \bar{w}_{n e t}\right)=\underline{m}=0$ initially. If mobility costs decline, then optimal public investment level, $\hat{G}$, remains unchanged. If $\bar{w}_{\text {net }}$ increases, then $\hat{G}$ declines.

(ii) Let $\hat{m}^{\text {high }}$ be the number of emigrants in a stable equilibrium $\hat{m}\left(\hat{G}, \bar{w}_{\text {net }}\right)>0$ where emigration is highest, given the optimal policy choice, $\hat{G}$. If mobility cost decline or if $\bar{w}_{\text {net }}$ increases, then $\hat{G}$ decreases and the corresponding equilibrium net wage rate for skilled labor, $\tilde{W}\left(\hat{m}^{\text {high }}, \hat{G}\right)$, declines.

(iii) Let $\hat{m}^{\text {low }}$ be the number of immigrants in a stable equilibrium $\hat{m}\left(\hat{G}, \bar{w}_{\text {net }}\right)<0$ where immigration is highest, given $\hat{G}$. If the economy becomes more prone to immigration or if $\bar{w}_{\text {net }}$ declines, then $\hat{G}$ increases and $\tilde{W}\left(\hat{m}^{\text {high }}, \hat{G}\right)$ increases.

Proposition 3 suggests that declining mobility costs not only accentuate migration flows and income differences among economies (Proposition 1), but also accentuate public investment spending levels: Economies which experience further brain drain optimally choose to lower public investment $\hat{G}$ whereas economies which experience further immigration of skilled labor increase $\hat{G}$. The intuition for this result can be seen from Figure 2, which depicts welfare $\tilde{W}(m, G)=W(m, b(G), G)$ for two levels of $m$.

\section{$<$ Figure 2 here $>$}

If the number of emigrants increases from $m_{1}$ to $m_{2}>m_{1}$ (or the number of immigrants decreases), not only net wages fall (recall $\tilde{W}_{m}=W_{m}<0$ ) but also the marginal gain in net wages from an increase in public investment $G$ declines $\left(\tilde{W}_{G m}<0\right)$. The latter property stems from a combination of two effects which go in the same direction: first, the marginal income gain from raising productivity $B$ declines if there is higher emigration (or less immigration) ${ }^{20}$ second, the necessary increase in the income tax rate when raising public infrastructure investment $G$ rises (so to balance the public budget). ${ }^{21}$ Graphically, as shown in Fig. 2, a higher migration outflow shifts welfare as a function of

\footnotetext{
${ }^{20}$ Formally, $W_{B m}<0$, according to (14).

${ }^{21}$ The latter property, $W_{G m}<0$, would modify to $W_{G m}=0$ if migrants would still have to pay taxes at home (for instance, because they commute for work abroad but live in the economy where they are born and residence-based taxation applies). Consequently, $\tilde{W}_{G m}<0$ would still hold in this case. Also the agglomeration effects which give rise to the possibility of multiple equilibria are only partly driven by the assumption that individuals are taxed where they work. All results would qualitatively remain the same if we relaxed that assumption. The crucial feature of the model are scale effects in wage levels, not tax effects.
} 
$G$ (which is strictly concave as we have already seen that $\tilde{W}_{G G}<0$ ) not only downward but also to the left.

For instance, if $\hat{m}>0$ is a stable equilibrium, then brain drain is accentuated if mobility cost decline or the net wage abroad, $\bar{w}_{n e t}$, rises (part (ii) of Proposition 1). As a result, welfare as a function of $G$ shifts as shown in Fig. 2 and the optimal infrastructure investment, $\hat{G}$, declines (part (ii) of Proposition 3). The other parts of Proposition 3 follow analogously.

We shall stress that we do not literally believe in the benevolent government for positive analysis. However, the changing trade-off between public investment provision and net wages after a change in the number of migrants may induce governments to reduce public spending even in more sophisticated political economy models.

\section{Empirical Evidence}

Two main hypotheses emerge from the theoretical section. The first one concerns the interaction between migration flows from or into an economy and wage income (relative to potential source or host economies). This interaction is reflected in Proposition 1 when holding the public infrastructure investment constant and in Proposition 3 when endogenous adjustment of $G$ is accounted for. The second hypothesis concerns the interaction between the adjustment of optimal public infrastructure investment $(\hat{G})$ and (endogenous) changes in migration flows, as suggested by Proposition 3. More precisely, the following testable predictions can be derived from the theoretical model.

- A higher income gap to potential host economies leads to a higher "emigration rate', i.e., the emigration level per skilled worker of an economy (Hypothesis 1a). This prediction captures that the emigration rate is an increasing function of the income gap $(\chi-1)$; formally, it follows from $m=\Phi(\chi-1) .{ }^{22}$

- The higher the income gap to potential host economies, the higher is the (sub-

\footnotetext{
${ }^{22}$ According to (12), the emigration rate is given by $m / H=(1+\alpha)[1-\beta+(\alpha+\beta) / m]^{-1}$. Thus, there is a positive relationship between $m$ and $m / H$. Bringing our model to the data, we focus on emigration rates $(m / H)$, rather than level $m$, to account for differences in population size.
} 
sequent) change in the emigration rate (Hypothesis 1b). This prediction follows from the insight that an integration of the market for skilled labor (reduction in mobility costs) induces higher emigration in a source economy, for a given income gap; the increased migration outflow reflects adjustment to equilibrium. ${ }^{23}$

- A higher emigration rate in an economy causes a higher income gap to other economies, all other things equal (Hypothesis 1c). This prediction reflects that brain drain induces scale effects (associated with the R\&D process) in our theoretical model which lead to increases in income gaps to other countries (increases in $\chi) ;{ }^{24}$ formally, the hypothesis reflects the relationship $\chi=\tilde{\chi}(m, \cdot)$.

- A change in emigration rates is positively related to a change in the income gap to potential host economies (Hypothesis 1d); both are simultaneously determined. This prediction captures the equilibrium interactions reflected in Proposition 1 (without adjustment in $G$ ) and Proposition 3 (with adjustment in $G$ ): for instance, if mobility costs decline, both income gaps and emigration rates increase.

- A change in the emigration rate is negatively related to a change in the public investment level (Hypothesis 2). Analogously to Hypothesis 1d, this prediction reflects that changes in $\hat{m}$ and changes in $\hat{G}$ are simultaneously triggered by exogenous events, like labor market integration, according to Proposition 3.

We ideally would want to construct net emigration rates, as countries are typically both source and host economies of skilled workers. Immigration data is, unfortunately, not available for a sufficiently large set of countries. However, the lack of immigration data may not lead to a large bias if countries with high gross emigration rates also have systematically higher net emigration rates, which seems plausible. Before we present empirical tests of the hypotheses, we first describe the data.

\footnotetext{
${ }^{23}$ Although the presented model is static for simplicity, the empirical analysis thus allows for adjustment processes. Formally, motivated by (16) and our notion of stability of equilibrium, one may think of an evolution of migration stock $m$ over time $(t)$ according to $m_{t}=\Phi\left(\tilde{\chi}\left(m_{t-1}, \cdot\right)-1\right)$.

${ }^{24}$ Whereas brain drain refers to emigration flows, the hypothesis relates the income gap to potential host economies of an economy to its emigration rate, that is, to its stock of emigration. As emigration stocks reflect accumulated migration outflows, the hypothesis refers to accumulated scale effects which amount to observed income gaps.
} 


\subsection{Data}

The first main variable of interest is the emigration rate of high skilled individuals. Docquier and Marfouk (2006) have established a dataset of emigration stocks and rates by educational attainment for the years 1990 and 2000. The authors count as emigrants all foreign-born individuals aged at least 25 who live in an OECD country and class them by educational attainment and country of origin. To obtain the emigration rate for a specific source country, the emigration stock is divided by the total number of people born in the source country and belonging to the same educational category. Thus, only emigration into OECD countries is captured, approximately $90 \%$ of educated migrants in the world. ${ }^{25}$ As we are interested in the migration pattern of high skilled individuals, we focus on emigration rates of the high educational category provided by Docquier and Marfouk (2006); it is denoted by Mig1990 and Mig2000 for the years 1990 and 2000, respectively.

Our second main variable of interest are income gaps to potential host or source economies (both triggering and being affected by migration). We take the difference between the median of log GDP per capita of the G7 countries and log GDP per capita of a country for the years 1990 and 2000 (GDPgap1990, GDPgap2000). ${ }^{26}$

Our theoretical analysis suggests that emigration rates are affected (besides by income gaps) by the distribution of mobility costs. To capture cross-country differences in mobility costs in our migration regressions (test of Hypotheses 1a and 1b), we also account for the notion that migration possibilities might be influenced by historical ties to other countries. For instance, a common language of host and source country is associated with low mobility costs for potential emigrants, all other things equal. This is captured by including legal origins of a country in the specifications (LegalBritish, LegalFrench). Moreover, emigration rates may be related to the population size (Pop) of a country, for at least two reasons. ${ }^{27}$ First, some host countries have immigration

\footnotetext{
${ }^{25}$ See Docquier and Makfouk (2006) for a detailed discussion concerning data collection and construction issues.

${ }^{26}$ Recall that in our theoretical model gross wage income $(w, q)$ and per capita GDP $(y)$ are proportional to each other. We take gross income levels as proxies for net income.

${ }^{27}$ We also experimented by using the area of countries as additional control; it has negligible effects once population size is accounted for and leaves other results basically unchanged.
} 
quotas which fix the maximum number of immigrants from a specific country. These quotas do not vary systematically with size of a source country. Thus, the possibility of emigration is lower (migration costs are higher) for larger countries than for smaller ones (Beine, Docquier and Rapoport, 2001). Second, workers with specific skills may find out that employment opportunities are better elsewhere due to asymmetric skill demand shocks across regions. Since in a larger country the dispersion in the demand for specific skills across regions is higher, there is less migration to foreign countries (and more internal migration) in larger countries in response to an adverse skill demand shock in a region. ${ }^{28}$ In sum, we expect higher population size to reduce the emigration rate.

In order to control for other factors than brain drain which may affect income gaps (test of Hypothesis 1c), we employ a number of additional standard controls (again, as gap to the median value in G7 countries of the respective variable). These are primary and tertiary school enrollment (PrimSchoolGap, TertSchoolGap), the investment share (InvestGap), and the share of urban population (UrbanGap). We also include geographical variables. These are supposed to capture income differences which could be led back to more fundamental factors.

Data availability allows us to employ observations for 77 countries to address Hypotheses 1a-1d. Table 1 provides the variable definitions, data sources, and country names; it also contains descriptive statistics of the employed variables.

\section{$<$ Table 1 here $>$}

To address Hypothesis 2, we employ several indicators for public infrastructure investment, $G$ : Government investment from the OECD database (focussing on OECD countries only), and two variables from the IMF Government Financial Statistics (available also for some non-OECD countries), "Government Acquisition of Fixed Assets" and "Government Capital Expenditure".

\footnotetext{
${ }^{28}$ See, for instance, Wildasin (2000) who points out that labor market integration insures workers with specific skills who face the risk of regional labor demand shocks.
} 


\subsection{Estimation Strategy}

Our empirical specifications have to deal with the problem of endogeneity. We solve this problem in two different ways: using lagged variables for Hypotheses 1a-1c and estimating a structural equation model for Hypotheses 1d. A structural equation model would also be required to test Hypothesis 2. Due to the lack of data for public investment for a broader range of countries, we unfortunately are confined to present simple correlations between changes in migration rates and changes in public investment measures to support Hypothesis 2.

Regarding Hypotheses 1a-1c, using lagged variables to identify specific mechanisms takes into account that migration reacts to income gaps with some delay, and vice versa. Hypothesis 1a then suggests to estimate:

$$
{\operatorname{Mig} 2000_{i}}=\alpha_{0}+\alpha_{1} \text { GDPgap } 1990_{i}+\mathbf{z}_{i}^{\prime} \boldsymbol{\alpha}_{z}+u_{i}
$$

where $i$ is the country index. The theoretical model predicts $\alpha_{1}>0$. To capture that migration rates still adjust after an exogenous event to an equilibrium (Hypothesis 1b), we also estimate

$$
\operatorname{DeltaMig}_{i}=\beta_{0}+\beta_{1} G D P g a p 1990_{i}+\mathbf{z}_{i}^{\prime} \boldsymbol{\beta}_{z}+\eta_{i},
$$

where DeltaMig $\equiv$ Mig2000 - Mig1990 is the change in the emigration rate. We expect that $\beta_{1} \geq 0$, with strict inequality when the (stable) stationary equilibrium has not yet been reached. Hypothesis 1c looks at the (accumulated) impact of emigration rates on income gaps, capturing scale effects present in the theoretical model with endogenous R\&D investments:

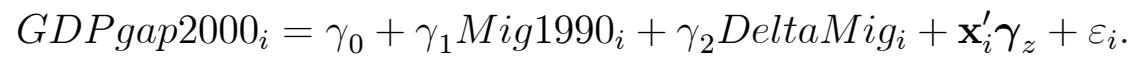

$\mathbf{x}$ and $\mathbf{z}$ denote vectors of controls (typically lagged variables), $u, \eta$ and $\varepsilon$ are error terms. Note we separate the effects until 1990 and after 1990 (until 2000). The theoretical model predicts $\gamma_{1}, \gamma_{2} \geq 0$. 
To address Hypothesis 1d, which refers to the equilibrium interaction between changes in emigration rates and income changes after exogenous events (Proposition 1 and 3), we estimate a structural equation model with a full information three stage least square (3SLS) estimator. ${ }^{29}$ We jointly estimate:

$$
\begin{aligned}
\text { DeltaMig }_{i} & =\delta_{0}+\delta_{1} \text { DeltaGDPgap } \\
\text { DeltaGDPgap } & =\tilde{\mathbf{z}}_{i}^{\prime} \boldsymbol{\delta}_{z}+\varsigma_{i} \\
& =\nu_{0}+\nu_{1} \text { DeltaMig }_{i}+\tilde{\mathbf{x}}_{i}^{\prime} \boldsymbol{\nu}_{z}+\xi_{i}
\end{aligned}
$$

where DeltaGDPgap $\equiv$ GDPgap2000 - GDPgap1990 is the change in the (log of) the income gap. $\tilde{\mathbf{x}}$ and $\tilde{\mathbf{z}}$ denote vectors of controls, $\varsigma$ and $\xi$ are error terms. The theoretical model suggests $\delta_{1}, \nu_{1}>0$. For identification we need to find instruments for the dependent variables in (21) and (22). As an instrument for the change in the emigration rate between 1990 and 2000 (DeltaMig) we use the emigration rate in 1990 (Mig1990). According to our model, we should find a positive relation between Mig1990 and DeltaMig. Proposition 1 suggests that emigration becomes more pronounced after labor market integration if there is already emigration, and analogously for immigration. ${ }^{30}$ Moreover, there does not seem to be an important reason why a higher initial emigration rate should affect changes in income gaps through other channels than its impact on the evolution of emigration patterns. As an instrument for the change in the income gap to median GDP per capita G7 countries between 1990 and 2000 (DeltaGap) we employ the investment share in 1990 (InvestS1990). This choice is motivated by neoclassical growth theory. We implicitly employ the notion that the investment share affects changes in emigration rates only through changing income gaps.

We test for possible endogeneity of the variables DeltaMig and DeltaGDPgap by using a Hausman (1978) specification test. Hausman (1978) originally proposed a test statistic for endogeneity based upon a direct comparison of coefficient values. Here, we use the Hausman test version proposed by Davidson and MacKinnon (1989), which

\footnotetext{
${ }^{29}$ A 3SLS estimator basically combines two stage least squares (2SLS) with seemingly unrelated regression (SUR). See supplementary material for details.

${ }^{30}$ This may hold also because a high level of immigrants in a country means that new immigrants may find a social network (for instance, consisting of emigrated relatives) in that country. In this sense, the mobility cost distribution may depend on past emigration.
} 
carries out the test by running an auxiliary regression. In the first regression, the suspect endogenous variable is regressed on all exogenous variables and the instruments to retrieve the residuals. Then in the second regression, the residuals are included as additional regressors in the estimation of interest. If the estimates are consistent, then the coefficient on the first stage residuals should not be significantly different from zero.

We also compare our 3SLS estimator to a 2SLS estimator by using another Hausman test. The null hypothesis of the test is that all exogenous variables are uncorrelated with the disturbance terms. In this case both the 2SLS and the 3SLS estimator are consistent but only the 3SLS estimator is (asymptotically) efficient. This is the main justification for us to use a 3SLS approach. Under the alternative hypothesis the 2SLS estimator is consistent but the 3SLS estimator is inconsistent.

\subsection{Results}

\section{$<$ Table 2 here $>$}

First we look at the effects of a country's income gap to potential host or source countries in 1990 on the emigration rate in 2000. The results in Tab. 2 are consistent with Hypothesis 1a. In the large sample (columns (1)-(5)), the coefficient on GDPgap1990 is positive $\left(\alpha_{1}>0\right)$ and statistically different from zero below the 5 percent level. Using weighted least squares (column (5)) rather than OLS does not change results substantially. Column (6) refers to an estimation with OECD countries only. The coefficient on GDPgap1990 becomes larger but somewhat less significant. As expected, higher population size $(P o p)$ has a negative and highly significant effect on the emigration rate. Legal origin is much less important, although an English legal origin seems to facilitate migration.

\section{$<$ Table 3 here $>$}

According to Tab. 3, which tests Hypothesis 1b, higher income gaps also seem to trigger increases in emigration rates in the expected way $\left(\beta_{1}>0\right)$. The interpretation is that past changes in mobility costs lead to equilibrium adjustment. A higher initial 
emigration rate (Mig1990) is also positively related to changes in the emigration rate (although significant between the 5 and 10 percent level only). This means that there is support for the notion that emigration becomes more pronounced over time (e.g., after an institutionally rooted decrease in mobility costs). Neither population size nor legal origin seem to affect changes in the migration pattern. Focussing on OECD countries only, coefficients on both GDPgap1990 and Mig1990 become insignificant, suggesting that within the OECD migration patterns are closer to equilibrium.

\section{$<$ Table 4 here $>$}

Tab. 4 shows how income (GDPgap2000) is affected by emigration patterns (Hypothesis 1c). It emerges that only more recent changes in emigration rates (DeltaMig) matter for income gaps to potential host countries $\left(\gamma_{2}>0\right)$ whereas migration flows before 1990 (captured by Mig1990) have no discernible effect $\left(\gamma_{1}\right.$ is never statistically different from zero and sometimes even has the "wrong" sign). Other control variables have the expected and often significant effects. For instance, a higher gap in school enrolment, investment and urban population to the G7 countries leads to higher income gaps. Not surprisingly, tropical countries or countries in Sub-Saharian Africa are on average poorer. ${ }^{31}$

\section{$<$ Figure 3 here $>$}

We next provide evidence which supports Hypothesis 1d. Fig. 3 provides the scatter plot for changes in emigration rates and changes in income gaps (to the median income of the G7) between 1990 and 2000 for our sample of 77 countries (not controlling for other factors). The correlation coefficient is almost .5 and highly significant.

\section{$<$ Table 5 here $>$}

Tab. 5 accounts for the endogeneity of both DeltaMig and DeltaGDPgap and their interaction. It presents the results on the structural equation model (21) and

\footnotetext{
${ }^{31}$ Latitude has no effect, however. We also experimented with inclusion of a dummy for East Asian Pacific countries, which however turned out to be unimportant (not shown).
} 
(22), including those from the Hausman tests. From the upper table we find that an increase in DeltaGDPgap positively affects the change in emigration rates $\left(\delta_{1}>0\right) ; \delta_{1}$ is statistically different from zero below the one percent level in all specifications. Also the effect of a higher DeltaMig on a change in the income gap is positive $\left(\nu_{1}>0\right)$ and highly significant in all 3SLS estimates (but less significant in 2SLS). In this second equation we also control for the initial GDP per capita gap (in 1990) as a "catch-all" variable for other sources (than changes in emigration rates) for changes in income gaps. Although GDPgap1990 is highly related to DeltaMig (according to the test results of Hypothesis 1b presented in Tab. 3), the coefficient on DeltaMig and its level of statistical significance is largely unchanged when GDPgap1990 is included. ${ }^{32}$

Looking at the p-values of the Hausman test statistics suggests that instrumenting is generally crucial and the instruments are chosen in an acceptable way. The instruments also seem to be well correlated with the endogenous variables (see notes to Tab. 5).

The comparison between the 2SLS and the 3SLS estimator indicates that it is preferable to use the 3SLS estimator as the p-value is always well above the 10-\%-level. This suggests, in sum, that the relationship between DeltaMig and DeltaGDPgap is not only positive but also highly significant in both directions (columns (1), (3), (5)).

\section{$<$ Figure 4 here $>$}

We finally come to evidence on our Hypothesis 2 on changes in emigration rates (DeltaMig) and changes in (optimal) public infrastructure investment $(\hat{G})$. According to Proposition 3, the variables are negatively related, i.e., countries with increased emigration after an exogenous shock are expected to decrease public investment. Fig. 4 suggests that this is indeed the case. Panel (a) shows that the relationship between DeltaMig and the change between 1990 and 2000 in government investment over GDP in the OECD. Panels (b) and (c) show that, for a broader set of countries, DeltaMig is also negatively related to the change government acquisition of fixed assets over GDP

\footnotetext{
${ }^{32}$ The coefficient on GDPgap1990 is only once, in column (3) of Tab. 5, statistically different from zero (and negative, which points to convergence among countries). Going from 3SLS to 2SLS (column (4)) or including geographical variables (columns (5) and (6)), it loses significance, however.
} 
and government capital expenditure over GDP. Measuring the public investment variables per worker (unlike in Fig. 4) rather than as a fraction of GDP changes the results only slightly. The correlation coefficient of DeltaMig and a change in government investment per worker in the OECD becomes $-0.519(\mathrm{p}$-value=0.016) and the correlation between DeltaMig and change in government acquisition of fixed assets per worker is -0.520 (p-value=0.011). However, the correlation between DeltaMig and government capital expenditure per worker drops to $-0.132(\mathrm{p}$-value $=0.444) .{ }^{33}$

\section{Concluding Remarks}

This paper analyzed the relationship between migration of high-skilled individuals, income gaps to potential host or source economies, and the optimal change in public infrastructure investment in response to endogenously changed migration flows. We showed that a decline in mobility costs increases emigration pressure for economies already suffering from brain drain, while benefitting those which were host economies to begin with. This holds true with and without optimal adjustment of public investment, suggesting that integration of labor markets for the highly skilled accentuates betweencountry income inequality. Higher outward migration is also associated with downward adjustment of public infrastructure investment. Cross-country evidence supports these theoretical hypotheses. As a caveat, we are well aware of the need to analyze data on net rather than gross emigration rates. Unfortunately, such a dataset is yet not available. Moreover, the 10 year period we are able to focus on in the empirical analysis may be too short to capture all relevant changes. One cannot rule out, for instance, that Eastern European countries which have seen a large outflow of skilled workers after 1990 may benefit in the longer run from return migration, remittances, or increased education levels.

Overall, we focussed on (and found evidence for) adverse brain drain effects. This matches with conjectures of policy makers in the EU. For instance, at a press conference

\footnotetext{
${ }^{33}$ One easily finds that the lower correlation coefficient is entirely due to one outlier: Iceland. Dropping Iceland we obtain a correlation coefficient of -0.428 which again is statistically different from zero at the one percent level.
} 
on October 23, 2007, the president of the European Commission discussed the EU "blue card" initiative by pointing out: "With regard to developing countries we are very much aware of the need to avoid negative "brain drain" effects. Therefore, the proposal promotes ethical recruitment standards to limit - if not ban - active recruitment by Member States in developing countries in some sensitive sectors" (SPEECH/07/650, p.3). The question is whether at the same time the persistent outflows of researchers and professional to, for instance, North America can be reversed. Our analysis cautions to have too optimistic expectations.

\section{Appendix}

Proof of Lemma 1. First, note that the inverse demand function of the final goods sector for input $Z$ is given by $p_{Z}=(1-\alpha) Y / Z[\equiv \partial Y / \partial Z]$. Substituting $p_{Z}=(1-\alpha) Y / Z$ into $w=p_{Z} \partial Z / \partial H_{Z}$ and using (2), we have $w=\beta(1-\alpha) Y / H_{Z}$. According to (1), (3) and $x(j)=\alpha^{\frac{2}{1-\alpha}} a(h) Z$ we find $Y=\alpha^{\frac{2 \alpha}{1-\alpha}} Z n a(h)$ for final output and thus

$$
w=\beta(1-\alpha) \alpha^{\frac{2 \alpha}{1-\alpha}} \frac{n a(h) Z}{H_{Z}} .
$$

Combining (7) and $(23)$ and recalling $\delta=(1-\alpha) \alpha^{\frac{1+\alpha}{1-\alpha}}$ leads to

$$
n=\frac{\alpha}{\beta} \frac{a^{\prime}(h)}{a(h)} H_{Z}
$$

Combining $w=p_{Z} \partial Z / \partial H_{Z}$ and $q=p_{Z} \partial Z / \partial L_{Z}$, the relative wage rate of skilled labor is given by $\frac{w}{q}=\frac{\beta}{1-\beta} \frac{L_{Z}}{H_{Z}}$, according to (2). Combining this with $w(1-\bar{e})=q$, we find that

$$
L_{Z}=L=\frac{1-\beta}{\beta(1-\bar{e})} H_{Z}
$$

Substituting (24) and (25) into (10) and using that $(h+f) a^{\prime}(h) / a(h)=1$, we can solve for $H_{Z}$ :

$$
H_{Z}=\frac{\beta(1-\bar{e})}{1+\alpha}(1-m) .
$$


Now substitute (25) into (2) and use (26) to find

$$
Z=B\left(\frac{1-\beta}{\beta(1-\bar{e})}\right)^{1-\beta} \frac{\beta(1-\bar{e})}{1+\alpha}(1-m)
$$

Substituting (27) into (7), $w=\delta Z a^{\prime}(h)$, confirms (11). To derive (12), substitute (26) into (25) and use $H=1-L$.

Proof of Lemma 2. We start with part (i). If $m \geq \underline{m}$ and therefore $\chi \geq 1$, then $m=\Phi(\chi-1)$, according to (13). Thus, according to (16) and $\Phi^{\prime}(\chi-1)=\varphi(\chi-1)$,

$$
M_{m}\left(m, G, \bar{w}_{n e t}\right)=\varphi\left(\tilde{\chi}\left(m, G, \bar{w}_{n e t}\right)-1\right) \tilde{\chi}_{m}\left(m, G, \bar{w}_{n e t}\right) .
$$

Since $\tilde{\chi}_{m}=-\bar{w}_{n e t} W_{m} / W^{2}>0$, according to (15), we find $M_{m}>0$. Moreover, (28) implies $M_{m m}=\varphi^{\prime}(\tilde{\chi}-1)\left(\tilde{\chi}_{m}\right)^{2}+\varphi(\chi-1) \tilde{\chi}_{m m}$, where $\tilde{\chi}_{m m}=\left[2\left(W_{m}\right)^{2}-W_{m m} W\right] \bar{w}_{n e t} / W^{3}$. It is easy to see from (14) that $W_{m m}<0$; thus, $\tilde{\chi}_{m m}>0$. Together with $\tilde{\chi}_{m}>0$, this confirms that $M_{m m}>0$ if $\varphi^{\prime}\left(\tilde{\chi}\left(m, G, \bar{w}_{n e t}\right)-1\right) \geq 0$, concluding the proof of part (i). Part (ii) follows from using (15) and $m=-I(\chi)$ if $\chi<1$, according to (13).

Proof of Proposition 1. Follows immediately from the discussion in the main text.

Proof of Proposition 2. The first-order condition to the maximization of $\hat{W}\left(G, \bar{w}_{\text {net }}\right)=$ $\tilde{W}\left(\hat{m}\left(G, \bar{w}_{n e t}\right), G\right)$ reads

$$
\left[\hat{W}_{G}\left(G, \bar{w}_{n e t}\right)=\right] \tilde{W}_{m}\left(\hat{m}\left(G, \bar{w}_{n e t}\right), G\right) \hat{m}_{G}\left(G, \bar{w}_{n e t}\right)+\tilde{W}_{G}\left(\hat{m}\left(G, \bar{w}_{n e t}\right), G\right)=0 .
$$

If $\hat{m} \geq 0$, by applying the implicit function theorem to (16), we obtain:

$$
\hat{m}_{G}\left(G, \bar{w}_{n e t}\right)=\frac{\varphi\left(\tilde{\chi}\left(\hat{m}, G, \bar{w}_{n e t}\right)-1\right) \tilde{\chi}_{G}\left(\hat{m}, G, \bar{w}_{n e t}\right)}{1-M_{m}\left(\hat{m}, G, \bar{w}_{n e t}\right)} .
$$

Note that the denominator is positive in stable equilibrium, i.e., $M_{m}\left(\hat{m}, G, \bar{w}_{n e t}\right)<1$. If $\hat{m}<0$, by applying the implicit function theorem to $m+I\left(\tilde{\chi}\left(m, G, \bar{w}_{\text {net }}\right)\right)=0$ (use part 
(ii) of Lemma 2), we find

$$
\hat{m}_{G}\left(G, \bar{w}_{n e t}\right)=-\frac{I^{\prime}\left(\tilde{\chi}\left(\hat{m}, G, \bar{w}_{n e t}\right)\right) \tilde{\chi}_{G}\left(\hat{m}, G, \bar{w}_{n e t}\right)}{1+I^{\prime}\left(\tilde{\chi}\left(\hat{m}, G, \bar{w}_{n e t}\right)\right) \tilde{\chi}_{m}\left(\hat{m}, G, \bar{w}_{n e t}\right)} .
$$

Again, in stable equilibrium, the denominator is positive. Moreover, using $\tilde{\chi}\left(\hat{m}, G, \bar{w}^{n e t}\right)=$ $\bar{w}^{n e t} / \tilde{W}(\hat{m}, G)$ from $(15)$, we find

$$
\tilde{\chi}_{G}\left(\hat{m}, G, \bar{w}^{n e t}\right)=-\frac{\bar{w}^{n e t}}{\tilde{W}(\hat{m}, G)^{2}} \tilde{W}_{G}(\hat{m}, G) .
$$

Suppose that $\hat{G}$ is given by first-order condition (29). (At the end of the proof we show that the second-order condition indeed holds.) Substituting (30) into (29) and using (32), we find that whenever the optimal public investment level, $\hat{G}$, is associated with emigration, then $\hat{G}$ is given by

$$
\left(1-\frac{\tilde{W}_{m}(\hat{m}, \hat{G}) \varphi\left(\tilde{\chi}\left(\hat{m}, G, \bar{w}_{n e t}\right)-1\right) \bar{w}_{n e t}}{\left[1-M_{m}\left(\hat{m}, G, \bar{w}_{n e t}\right)\right] \tilde{W}(\hat{m}, G)^{2}}\right) \tilde{W}_{G}(\hat{m}, \hat{G})=0 .
$$

As the term in large brackets is positive in stable equilibrium (use $M_{m}<1$ and $\tilde{W}_{m}<0$ ), $\hat{G}$ is given by $\tilde{W}_{G}(\hat{m}, \hat{G})=0$, which holds if and only if $\hat{m}_{G}\left(\hat{G}, \bar{w}_{n e t}\right)=0$, according to (30) and (32).

Similarly, using (31) and (32), the first-order condition (29) can be rewritten to

$$
\left(1+\frac{\tilde{W}_{m}(\hat{m}, \hat{G}) I^{\prime}\left(\tilde{\chi}\left(\hat{m}, G, \bar{w}_{n e t}\right)\right) \bar{w}_{n e t}}{\left[1+I^{\prime}\left(\tilde{\chi}\left(\hat{m}, G, \bar{w}_{n e t}\right)\right) \tilde{\chi}_{m}\left(\hat{m}, G, \bar{w}_{n e t}\right)\right] \tilde{W}(\hat{m}, G)^{2}}\right) \tilde{W}_{G}(\hat{m}, \hat{G})=0
$$

Again, the term in large brackets is positive in stable equilibrium (use $I^{\prime}<0, \tilde{W}_{m}<0$ and $\left.1+I^{\prime}(\tilde{\chi}) \tilde{\chi}_{m}>0\right)$. Thus, again, $\hat{G}$ is given by $\tilde{W}_{G}(\hat{m}, \hat{G})=0$, which holds if and only if $\hat{m}_{G}\left(\hat{G}, \bar{w}_{n e t}\right)=0$, according to (31) and (32).

We next show that the second-order condition holds, i.e., $\hat{W}_{G G}\left(\hat{G}, \bar{w}_{\text {net }}\right)<0$. To see this, note that we just established that $\hat{W}_{G}\left(\hat{G}, \bar{w}_{n e t}\right)=\tilde{W}_{G}\left(\hat{m}\left(\hat{G}, \bar{w}_{\text {net }}\right), \hat{G}\right)=0$ when $\hat{G}$ 
is given by first-order condition (29). Hence,

$$
\hat{W}_{G G}\left(\hat{G}, \bar{w}_{n e t}\right)=\tilde{W}_{G m}\left(\hat{m}\left(\hat{G}, \bar{w}_{n e t}\right), \hat{G}\right) \hat{m}_{G}\left(\hat{G}, \bar{w}_{n e t}\right)+\tilde{W}_{G G}\left(\hat{m}\left(\hat{G}, \bar{w}_{n e t}\right), \hat{G}\right) .
$$

Using $\hat{m}_{G}\left(\hat{G}, \bar{w}_{n e t}\right)=0$, we thus have $\hat{W}_{G G}\left(\hat{G}, \bar{w}_{n e t}\right)=\left.\tilde{W}_{G G}\right|_{G=\hat{G}} \cdot{ }^{34}$ Recalling that $\tilde{W}_{G G}<0$ confirms that the second-order condition holds.

Finally, we have to show that $\hat{m}_{G G}\left(\hat{G}, \bar{w}_{\text {net }}\right)>0$ holds, which means that emigration from a source economy $(\hat{m}>0)$ is minimized and immigration to a host economy $(I=$ $-\hat{m})$ is maximized. From $(32)$ and $\left.\tilde{W}_{G}\right|_{G=\hat{G}}=0$ we have $\left.\tilde{\chi}_{G}\right|_{G=\hat{G}}=0$ and $\left.\tilde{\chi}_{G G}\right|_{G=\hat{G}}=$ $\left.\left[-\bar{w}_{n e t} \tilde{W}_{G G} / \tilde{W}\right]\right|_{G=\hat{G}}>0 . \tilde{W}_{G G}<0$ implies $\left.\tilde{\chi}_{G G}\right|_{G=\hat{G}}>0$. This property will now be used. We start with emigration, $\hat{m}\left(\hat{G}, \bar{w}_{n e t}\right) \geq 0$. According to (30) and $\left.\tilde{\chi}_{G}\right|_{G=\hat{G}}=0$, we obtain

$$
\hat{m}_{G G}\left(\hat{G}, \bar{w}_{n e t}\right)=\left.\left[\frac{\varphi(\tilde{\chi}-1) \tilde{\chi}_{G G}}{1-M_{m}}\right]\right|_{G=\hat{G}}>0
$$

by using $\left.\tilde{\chi}_{G G}\right|_{G=\hat{G}}>0$ and the fact that the denominator is positive in stable equilibrium. Similarly, when $\hat{m}\left(\hat{G}, \bar{w}_{n e t}\right)<0$, then $(31)$ and $\left.\tilde{\chi}_{G}\right|_{G=\hat{G}}=0$ imply

$$
\hat{m}_{G G}\left(\hat{G}, \bar{w}_{n e t}\right)=\left.\left[\frac{-I(\tilde{\chi}) \tilde{\chi}_{G G}}{1+I^{\prime}(\tilde{\chi}) \tilde{\chi}_{m}}\right]\right|_{G=\hat{G}}>0
$$

by using $I^{\prime}<0,\left.\tilde{\chi}_{G G}\right|_{G=\hat{G}}>0$ and the fact that the denominator is positive. This concludes the proof.

Proof of Proposition 3. Note that $\tilde{W}_{G m}=W_{B m} b^{\prime}+W_{G m}$. From (14), we have $W_{B m}<0$ and $W_{G m}<0$, which implies $\tilde{W}_{G m}<0$. The result follows from the discussion in the main text.

\section{References}

[1] Andersen, Torben M. (2005). Migration, taxation and educational incentives, Economics Letters 87, 399-405.

\footnotetext{
${ }^{34}$ With respect to a function $F(m, G, \cdot)$, we employ the short-cut notation $\left.F\right|_{G=\hat{G}}$ to indicate $F\left(\hat{m}\left(\hat{G}, \bar{w}_{n e t}\right), \hat{G}, \cdot\right)$ in what follows.
} 
[2] Andersson, Fredrik and Kai A. Konrad (2003). Human capital investment and globalization in extortionary states, Journal of Public Economics 87, 1539-1555.

[3] Auriol, Laudeline (2007). Labour market characteristics and international mobility of doctorate holders: Results for seven countries, OECD STI Working Paper 2007/2.

[4] Bhagwati, Jagdish N. and Koichi Hamada (1974). The brain drain, international integration of markets for professionals and unemployment, Journal of Development Economics 1, 19-42.

[5] Bhagwati, Jagdish N. and John D. Wilson, eds. (1989). Income Taxation and International Mobility, Cambridge, MA: MIT Press.

[6] Beine, Michel, Frédéric Docquier and Hillel Rapoport (2001). Brain drain and economic growth: theory and evidence, Journal of Development Economics 64, 275-89.

[7] Beine, Michel, Frederic Docquier and Hillel Rapoport (2008). Brain drain and human capital formation in developing countries: winners and losers, Economic Journal, forthcoming.

[8] Davidson, Russell and James G. MacKinnon (1989). Testing for consistency using artificial regressions, Econometric Theory 5, 363-384.

[9] Docquier, Frédéric and Aldeslam Marfouk (2006). International migration by educational attainment (1990-2000) - Release 1.1, in: C. Ozden and M. Schiff (eds), International Migration, Remittances and Development, Palgrave Macmillan, New York.

[10] Dumont, Jean-Christophe and Georges Lemaître (2005). Counting immigrants and expatriates in OECD countries: A new perspective, OECD Social Employment and Migration Working Papers, No. 25, OECD, Paris.

[11] Egger, Hartmut, Josef Falkinger and Volker Grossmann (2007). Brain drain, fiscal competition, and public education expenditure, University of Zurich, mimeo. 
[12] European Commission (2003). Third European Report on Science \& Technology Indicators 2003: Towards a Knowledge-based Economy, http://cordis.europa.eu/indicators/third_report.htm.

[13] Grossmann, Volker (2008). Entrepreneurial Innovation and Sustained Long-run Growth Without Weak or Strong Scale Effects, University of Fribourg, mimeo.

[14] Grossmann, V. and T.M. Steger (2007). Growth, development, and technological change, in: Wei-Bin Zhang (ed.), UNESCO Encyclopedia of Life Support Systems (Mathematical Models in Economics), Eolss Publishers, Oxford, UK.

[15] Hausman, Jerry A. (1978). Specification tests in econometrics, Econometrica 46, $1251-1271$.

[16] Jones, Charles I. (2005). Growth and ideas, in: P. Aghion and S. Durlauf (eds.), Handbook of Economic Growth, North-Holland, Amsterdam.

[17] Laincz, Christopher A. and Pietro F. Peretto (2006). Scale effects in endogenous growth theory: An error of aggregation not specification, Journal of Economic Growth 11, 263-288.

[18] Haupt, Alexander and Eckhard Janeba (2004). Education, redistribution, and the threat of brain drain, NBER Working Paper No. 10618.

[19] Miyagiwa, Kaz (1991). Scale economies in education and the brain drain problem, International Economic Review 32, 743-759.

[20] Mountford, Andrew (1997). Can a brain drain be good for growth in the source economy?, Journal of Development Economics 53, 287-303.

[21] OECD (2007a). OECD Science, Technology and Industry Scoreboard 2007, OECD, Paris.

[22] OECD (2007b). International Migration Outlook, Annual Report 2007, OECD, Paris. 
[23] Poutvaara, Panu and Vesa Kanniainen (2000). Why Invest in Your Neighbor? Social Contract on Educational Investment, International Tax and Public Finance 7, 547562.

[24] Saint-Paul, Gilles (2004). The brain drain: Some evidence from European expatriates in the United States, IZA Discussion Paper No. 1310.

[25] Stark, Oded, Christian Helmenstein and Alexia Prskawetz (1997). A brain gain with a brain drain, Economics Letters 55 (2), 227-234.

[26] Stark, Oded, Christian Helmenstein, Alexia Prskawetz (1998). Human capital depletion, human capital formation, and migration: a blessing in a 'curse'?, Economics Letters 60, 363-367.

[27] Sutton, John (1998). Technology and Market Structure, Cambridge: MIT Press.

[28] Wildasin David (2000). Labor-market integration, investment in risky human capital, and fiscal competition, American Economic Review 90, 73-95.

\section{Supplementary Material: The Structural Equation Model}

In the structural equation model (Hypothesis 1d), we have two equations in our system, (21) and (22). Let us write them more generally as

$$
\begin{aligned}
\mathbf{y}_{k} & =\mathbf{Y}_{k} \boldsymbol{\beta}_{k}+\mathbf{X}_{k} \boldsymbol{\gamma}_{k}+u_{i} \\
& =\mathbf{T}_{k} \boldsymbol{\delta}_{k}+u_{k}, k \in\{1,2\}, \text { with } \mathbf{T}_{k} \equiv\left(\mathbf{Y}_{k} \mathbf{X}_{k}\right), \boldsymbol{\delta}_{k} \equiv\left(\boldsymbol{\beta}_{k} \boldsymbol{\gamma}_{k}\right)
\end{aligned}
$$

where $\mathbf{y}_{k}$ is the $N \times 1$ vector of observations on the endogenous variable in equation $k=1,2, \mathbf{Y}_{k}$ is the $N \times 1$ vector of observations on the endogenous variable included as a regressor in equation $k$, and $\mathbf{X}_{k}$ is the $N \times M$ matrix of observations on the $M$ 
predetermined variables in equation $k$. The two equations can always be written as seemingly unrelated in the following form

$$
\left[\begin{array}{l}
\mathbf{y}_{1} \\
\mathbf{y}_{2}
\end{array}\right]=\left[\begin{array}{cc}
\mathbf{T}_{1} & 0 \\
0 & \mathbf{T}_{2}
\end{array}\right]\left[\begin{array}{l}
\boldsymbol{\delta}_{1} \\
\boldsymbol{\delta}_{2}
\end{array}\right]+\underbrace{\left[\begin{array}{l}
u_{1} \\
u_{2}
\end{array}\right]}_{\mathbf{u}} .
$$

We assume that $\mathbf{u} \sim\left(0, \Sigma_{2 \times 2} \otimes I_{N}\right)$, where $\Sigma_{2 \times 2}$ is a variance-covariance matrix with constant variances of $u_{1}, u_{2}$, and $I_{N}$ is the $N \times N$ identity matrix.

In the first stage, we regress for $(k=1,2) \mathbf{Y}_{k}$ on $\mathbf{X}_{1}, \mathbf{X}_{2}$ and $\mathbf{Y}_{j}, j \neq k$, in order to obtain estimates $\hat{\mathbf{Y}}_{1}, \hat{\mathbf{Y}}_{2}$. In the second stage, the endogenous variable of equation $k$, $\mathbf{y}_{k}$ is regressed on $\hat{\mathbf{Y}}_{k}$ as well as the predetermined variables of this equation, $\mathbf{X}_{k}$. This leads to estimators $\hat{\boldsymbol{\delta}}_{1}, \hat{\boldsymbol{\delta}}_{2}$. In the case of a three stage estimation, we form an estimate for $\Sigma_{2 \times 2}$ from the residuals of the second stage and calculate feasible GLS estimators $\hat{\boldsymbol{\delta}}_{1}^{*}$, $\hat{\boldsymbol{\delta}}_{2}^{*}$. This type of estimator is provided in the package "systemfit" from the "R Project for Statistical Computing". 
Table 1

Data description and sources

\begin{tabular}{|c|c|c|c|c|}
\hline Variable & Description and source & Range & Mean & S.d. \\
\hline Mig1990 & $\begin{array}{l}\text { Stock of emigration of educational category } \\
\text { "high" divided by stock of individuals aged } 25+\text { of } \\
\text { the educational category "high" in } 1990 \text { (in } \\
\text { percent). Docquier and Marfouk (2006). }\end{array}$ & {$[0.46,52.52]$} & 12.920 & 11.566 \\
\hline Mig2000 & $\begin{array}{l}\text { As above but for year 2000. Docquier and } \\
\text { Marfouk (2006). }\end{array}$ & {$[0.17,44.17]$} & 12.460 & 10.750 \\
\hline DeltaMig & Mig2000 minus Mig1990. & {$[-13.57,18.52]$} & 0.460 & 4.806 \\
\hline GDPgap1990 & $\begin{array}{l}\text { Log GDP per capita gap to median log GDP per } \\
\text { capita of G7 countries in 1990. Penn World Table } \\
\text { Version 6.2. }\end{array}$ & {$[-0.23,3.95]$} & 1.420 & 1.183 \\
\hline GDPgap2000 & $\begin{array}{l}\text { As above but for year 2000. Penn World Table } \\
\text { Version } 6.2 \text {. }\end{array}$ & {$[-0.32,3.89]$} & 1.415 & 1.253 \\
\hline DeltaGDPgap & GDPgap2000 minus GDPgap1990 & {$[-0.423,0.611]$} & -0.0046 & 0.2069 \\
\hline PrimSchoolGap1990 & $\begin{array}{l}\text { Primary school enrolment gap to median of G7 } \\
\text { countries in 1990. Global Development Finance } \\
\text { \& World Development Indicators. }\end{array}$ & {$[-20.4,74.2]$} & 6.501 & 18.321 \\
\hline TertSchoolGap1990 & $\begin{array}{l}\text { Tertiary school enrolment gap to median of G7 } \\
\text { countries in 1990. Global Development Finance } \\
\text { \& World Development Indicators. }\end{array}$ & {$[-60.8,33.6]$} & 15.240 & 17.696 \\
\hline InvestGap1990 & $\begin{array}{l}\text { Investment share gap to median of G7 countries } \\
\text { in 1990. Penn World Table Version 6.2. }\end{array}$ & {$[-22.98,23.43]$} & 9.017 & 9.853 \\
\hline UrbanGap1990 & $\begin{array}{l}\text { Urban population share gap to median of G7 } \\
\text { countries in 1990. Global Development Finance } \\
\text { \& World Development Indicators. }\end{array}$ & {$[-23.42,71.26]$} & 23.390 & 26.730 \\
\hline InvestS1990 & $\begin{array}{l}\text { Investment share in 1990. Penn World Table } \\
\text { Version 6.2. }\end{array}$ & {$[2.47,48.88]$} & 16.88 & 9.853 \\
\hline LegalBritish & Legal origin: British. The World Bank. & $\{0,1\}$ & 0.351 & 0.480 \\
\hline LegalFrench & Legal origin: French. The World Bank. & $\{0,1\}$ & 0.429 & 0.498 \\
\hline Latitude & Latitude. The World Bank. & {$[-36.89,63.89]$} & 16.830 & 28.053 \\
\hline Tropical & Tropical. The World Bank. & $\{0,1\}$ & 0.455 & 0.501 \\
\hline Pop & $\begin{array}{l}\text { Population Size in } 1990 \text { (in thousands). Penn } \\
\text { World Table Version 6.2. }\end{array}$ & {$[254.8,841700]$} & 40740 & 102594 \\
\hline RegionSsa & Region: Sub Sahara Africa. The World Bank. & $\{0,1\}$ & 0.247 & 0.434 \\
\hline
\end{tabular}


Table 2

Hypothesis 1a: Effect of income gaps on emigration rates

\begin{tabular}{|c|c|c|c|c|c|c|}
\hline Variable & $\begin{array}{l}O L S \\
(1)\end{array}$ & $\begin{array}{l}O L S \\
(2)\end{array}$ & $\begin{array}{l}O L S \\
\text { (3) }\end{array}$ & $\begin{array}{l}O L S \\
(4)\end{array}$ & $\begin{array}{c}W L S \\
(5)\end{array}$ & $\begin{array}{l}O L S \\
(6)\end{array}$ \\
\hline \multicolumn{7}{|c|}{ Hypothesis 1a - Dependent variable: Mig2000 } \\
\hline (incercept) & $\begin{array}{c}9.2041^{\mathrm{a}} \\
(1.6223)\end{array}$ & $\begin{array}{l}10.0038^{a} \\
(1.6153)\end{array}$ & $\begin{array}{l}8.5204^{a} \\
(1.5595)\end{array}$ & $\begin{array}{l}10.8606^{a} \\
(2.2801)\end{array}$ & $\begin{array}{l}10.4618^{a} \\
(2.1098)\end{array}$ & $\begin{array}{l}11.8332^{\mathrm{a}} \\
(2.0718)\end{array}$ \\
\hline GDPgap1990 & $\begin{array}{l}2.2924^{\mathrm{b}} \\
(1.0907)\end{array}$ & $\begin{array}{l}2.4145^{b} \\
(1.0690)\end{array}$ & $\begin{array}{l}2.1868^{b} \\
(0.9877)\end{array}$ & $\begin{array}{l}2.3508^{b} \\
(0.9940)\end{array}$ & $\begin{array}{l}2.5358^{b} \\
(0.9700)\end{array}$ & $\begin{array}{l}3.8410^{c} \\
(2.1279)\end{array}$ \\
\hline$P o p$ & & $\begin{array}{c}-2.39 \mathrm{E}-5^{\mathrm{a}} \\
(8.15 \mathrm{E}-6)\end{array}$ & $\begin{array}{l}-2.79 \mathrm{E}-5^{\mathrm{a}} \\
(8.48 \mathrm{E}-6)\end{array}$ & $\begin{array}{l}-2.76 \mathrm{E}-5^{\mathrm{a}} \\
(8.16 \mathrm{E}-6)\end{array}$ & $\begin{array}{l}-2.63 \mathrm{E}-5^{\mathrm{a}} \\
(7.30 \mathrm{E}-6)\end{array}$ & $\begin{array}{l}-5.86 \mathrm{E}-5^{\mathrm{a}} \\
(2.06 \mathrm{E}-5)\end{array}$ \\
\hline LegalBritish & & & $\begin{array}{l}5.6181^{b} \\
(2.7601)\end{array}$ & $\begin{array}{c}2.9993 \\
(3.3837)\end{array}$ & $\begin{array}{c}2.7783 \\
(3.2142)\end{array}$ & \\
\hline LegalFrench & & & & $\begin{array}{l}-3.8871 \\
(2.4745)\end{array}$ & $\begin{array}{l}-3.7925 \\
(2.2996)\end{array}$ & \\
\hline multiple R2 & 0.0636 & 0.1154 & 0.1762 & 0.1952 & 0.2144 & 0.2204 \\
\hline $\mathrm{N}$ & 77 & 77 & 77 & 77 & 77 & 25 (OECD) \\
\hline
\end{tabular}

Notes: Robust standard errors in parenthesis. ${ }^{a}$ indicates a significance level of below $1 \%$; ${ }^{\mathrm{b}}$ indicates a significance level between 1 and $5 \%$; indicates significance level between 5 and $10 \%$. WLS in (5) refers to weighted least squares estimation which uses log(Pop) as weights. 
Table 3

Hypothesis 1b: Effect of income gaps on changes in emigration rates

\begin{tabular}{|c|c|c|c|c|c|c|c|}
\hline Variable & $\begin{array}{l}O L S \\
\text { (1) }\end{array}$ & $\begin{array}{l}O L S \\
(2)\end{array}$ & $\begin{array}{l}O L S \\
\text { (3) }\end{array}$ & $\begin{array}{l}O L S \\
(4)\end{array}$ & $\begin{array}{c}O L S \\
(5)\end{array}$ & $\begin{array}{c}W L S \\
(6)\end{array}$ & $\begin{array}{l}O L S \\
\text { (7) }\end{array}$ \\
\hline \multicolumn{8}{|c|}{ Hypothesis 1b - Dependent variable: DeltaMig } \\
\hline (incercept) & $\begin{array}{c}-1.3849 \mathrm{~b} \\
(0.5790)\end{array}$ & $\begin{array}{c}-1.3942^{\mathrm{b}} \\
(0.5802)\end{array}$ & $\begin{array}{l}-1.0945^{c} \\
(0.6226)\end{array}$ & $\begin{array}{c}-0.8198 \\
(0.7428)\end{array}$ & $\begin{array}{l}-2.0850^{c} \\
(1.2250)\end{array}$ & $\begin{array}{c}-1.8720 \\
(1.1681)\end{array}$ & $\begin{array}{c}0.2283 \\
(0.6397)\end{array}$ \\
\hline GDPgap1990 & $\begin{array}{c}1.3000^{\mathrm{a}} \\
(0.4917)\end{array}$ & $\begin{array}{l}1.2986^{\mathrm{b}} \\
(0.4976)\end{array}$ & $\begin{array}{l}1.3446^{\mathrm{a}} \\
(0.4824)\end{array}$ & $\begin{array}{c}1.3639^{a} \\
(0.4803)\end{array}$ & $\begin{array}{c}0.8798^{b} \\
(0.3591)\end{array}$ & $\begin{array}{c}0.8180^{\mathrm{b}} \\
(0.3328)\end{array}$ & $\begin{array}{c}0.8451 \\
(1.4353)\end{array}$ \\
\hline Pop & & $\begin{array}{l}2.76 \mathrm{E}-07 \\
(2.00 \mathrm{E}-6)\end{array}$ & & & & & \\
\hline LegalBritish & & & $\begin{array}{l}-1.0088 \\
(1.2185)\end{array}$ & $\begin{array}{l}-1.3143 \\
(1.2149)\end{array}$ & $\begin{array}{l}-1.4061 \\
(1.2386)\end{array}$ & $\begin{array}{l}-1.3197 \\
(1.1810)\end{array}$ & \\
\hline LegalFrench & & & & $\begin{array}{l}-0.4550 \\
(0.8827)\end{array}$ & $\begin{array}{c}0.1441 \\
(0.9777)\end{array}$ & $\begin{array}{c}0.0810 \\
(0.9222)\end{array}$ & \\
\hline Mig1990 & & & & & $\begin{array}{l}0.1337 \text { c } \\
(0.0755)\end{array}$ & $\begin{array}{c}0.1285^{c} \\
(0.0758)\end{array}$ & $\begin{array}{l}-0.0878 \\
(0.1076)\end{array}$ \\
\hline multiple R2 & 0.1024 & 0.1024 & 0.1123 & 0.1137 & 0.1987 & 0.1883 & 0.0653 \\
\hline $\mathrm{N}$ & 77 & 77 & 77 & 77 & 77 & 77 & 25 (OECD) \\
\hline
\end{tabular}




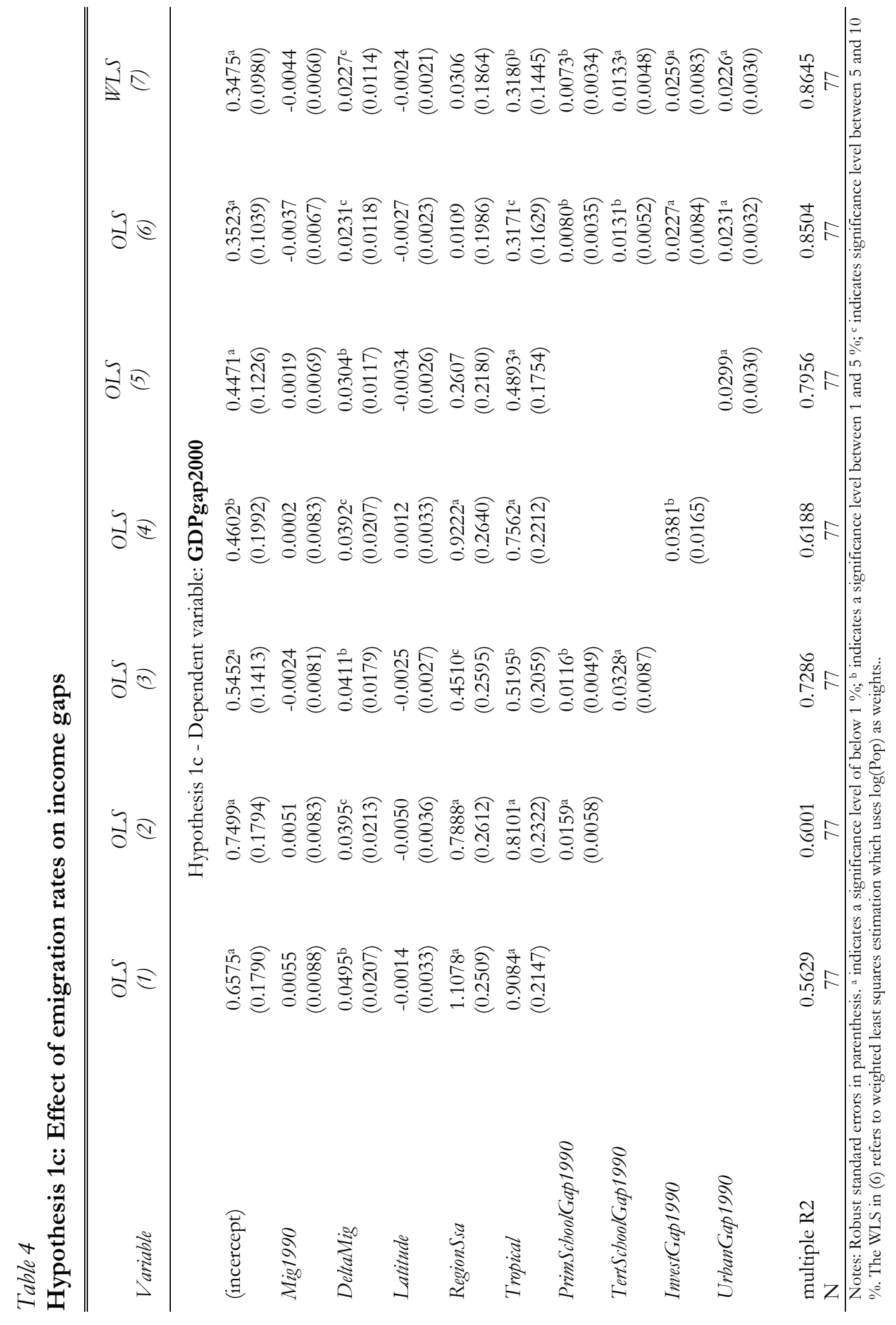


Table 5

Structural equation model for changes in income gaps and changes in emigration rates

\begin{tabular}{|c|c|c|c|c|c|c|}
\hline Variable & $\begin{array}{l}3 S L S \\
(1)\end{array}$ & $\begin{array}{l}2 S L S \\
\text { (2) }\end{array}$ & $\begin{array}{l}3 S L S \\
\text { (3) }\end{array}$ & $\begin{array}{l}2 S L S \\
(4)\end{array}$ & $\begin{array}{l}3 S L S \\
(5)\end{array}$ & $\begin{array}{c}2 S L S \\
(6)\end{array}$ \\
\hline \multicolumn{7}{|c|}{ Equation 1 - Dependent variable: DeltaMig } \\
\hline (incercept) & $\begin{array}{c}0.6512 \\
(0.5964)\end{array}$ & $\begin{array}{c}0.3176 \\
(0.6305)\end{array}$ & $\begin{array}{c}0.2929 \\
(0.6450)\end{array}$ & $\begin{array}{c}0.0509 \\
(0.7895)\end{array}$ & $\begin{array}{c}0.6670 \\
(0.9515)\end{array}$ & $\begin{array}{c}0.0198 \\
(1.1016)\end{array}$ \\
\hline DeltaGDPgap & $\begin{array}{l}17.0301^{\mathrm{a}} \\
(4.9977)\end{array}$ & $\begin{array}{l}15.4904^{\mathrm{a}} \\
(5.0619)\end{array}$ & $\begin{array}{l}33.5241^{\mathrm{a}} \\
(6.0637)\end{array}$ & $\begin{array}{c}26.6508^{a} \\
(9.6115)\end{array}$ & $\begin{array}{l}17.7819^{\mathrm{a}} \\
(5.0187)\end{array}$ & $\begin{array}{l}16.5822^{a} \\
(5.1563)\end{array}$ \\
\hline Pop & & & & & $\begin{array}{l}2.32 \mathrm{E}-6 \\
(3.96 \mathrm{E}-6)\end{array}$ & $\begin{array}{c}5.25 \mathrm{E}-6 \\
(5.17 \mathrm{E}-6)\end{array}$ \\
\hline LegalBritish & $\begin{array}{l}-0.3197 \\
(0.9646)\end{array}$ & $\begin{array}{c}0.6114 \\
(1.1231)\end{array}$ & $\begin{array}{c}0.9196 \\
(0.6719)\end{array}$ & $\begin{array}{c}1.5191 \\
(1.4961)\end{array}$ & $\begin{array}{l}-0.4914 \\
(1.2600)\end{array}$ & $\begin{array}{c}0.6431 \\
(1.4494)\end{array}$ \\
\hline LegalFrench & & & & & $\begin{array}{l}-0.1088 \\
(1.0544)\end{array}$ & $\begin{array}{c}0.1821 \\
(1.3304)\end{array}$ \\
\hline Hausman test ( $\mathrm{p}$-value) & \multicolumn{2}{|c|}{0.3193} & \multicolumn{2}{|c|}{0.0332} & \multicolumn{2}{|c|}{0.1965} \\
\hline \multicolumn{7}{|c|}{ Equation 2 - Dependent variable: DeltaGDPgap } \\
\hline (incercept) & $\begin{array}{l}-0.0634^{c} \\
(0.0338)\end{array}$ & $\begin{array}{c}-0.0930^{\mathrm{b}} \\
(0.0385)\end{array}$ & $\begin{array}{c}0.0113 \\
(0.0270)\end{array}$ & $\begin{array}{l}-0.0324 \\
(0.0389)\end{array}$ & $\begin{array}{l}-0.0556 \\
(0.0381)\end{array}$ & $\begin{array}{c}-0.0810^{c} \\
(0.0454)\end{array}$ \\
\hline DeltaMig & $\begin{array}{c}0.0391 \mathrm{a} \\
(0.0090)\end{array}$ & $\begin{array}{l}0.0200^{c} \\
(0.0116)\end{array}$ & $\begin{array}{c}0.0490^{\mathrm{a}} \\
(0.0044)\end{array}$ & $\begin{array}{c}0.0270^{c} \\
(0.0144)\end{array}$ & $\begin{array}{l}0.0366^{\mathrm{a}} \\
(0.0090)\end{array}$ & $\begin{array}{c}0.0194 \mathrm{c} \\
(0.0115)\end{array}$ \\
\hline Latitude & $\begin{array}{c}0.0007 \\
(0.0007)\end{array}$ & $\begin{array}{c}0.0014 \\
(0.0009)\end{array}$ & & & $\begin{array}{c}0.0007 \\
(0.0007)\end{array}$ & $\begin{array}{c}0.0014 \\
(0.0009)\end{array}$ \\
\hline RegionSsa & $\begin{array}{c}0.0791 \\
(0.0581)\end{array}$ & $\begin{array}{c}0.1484^{b} \\
(0.0645)\end{array}$ & & & $\begin{array}{c}0.0972^{c} \\
(0.0570)\end{array}$ & $\begin{array}{c}0.1678^{b} \\
(0.0641)\end{array}$ \\
\hline Tropical & $\begin{array}{c}0.0193 \\
(0.0364)\end{array}$ & $\begin{array}{c}0.0407 \\
(0.0479)\end{array}$ & & & $\begin{array}{c}0.0304 \\
(0.0403)\end{array}$ & $\begin{array}{c}0.0562 \\
(0.0527)\end{array}$ \\
\hline GDPgap1990 & & & $\begin{array}{c}-0.0271^{b} \\
(0.0121)\end{array}$ & $\begin{array}{c}0.0108 \\
(0.0260)\end{array}$ & $\begin{array}{l}-0.0108 \\
(0.0205)\end{array}$ & $\begin{array}{l}-0.0162 \\
(0.0271)\end{array}$ \\
\hline Hausman test ( $\mathrm{p}$-value) & \multicolumn{2}{|c|}{0.5735} & \multicolumn{2}{|c|}{0.5391} & \multicolumn{2}{|c|}{0.2733} \\
\hline Hausman (2SLS vs 3SLS) & \multicolumn{2}{|c|}{0.3579} & \multicolumn{2}{|c|}{0.4477} & \multicolumn{2}{|c|}{0.2831} \\
\hline $\mathrm{N}$ & \multicolumn{2}{|c|}{77} & \multicolumn{2}{|c|}{77} & \multicolumn{2}{|c|}{77} \\
\hline
\end{tabular}

Notes: a indicates a significance level of below $1 \%$; ${ }^{b}$ indicates a significance level between 1 and $5 \%$; indicates significance level between 5 and $10 \%$. The Hausman test for endogeneity is carried out by running an auxiliary regression. In the first regression, the suspect endogenous variable is regressed on all exogenous variables and the instrument to retrieve the residuals. Then in the second regression, the residuals are included as additional regressors in the estimation of interest. If the estimates are consistent, then the coefficient on the first stage residuals should not be significantly different from zero. Here we report the p-value for the coefficient of the residuals. In the first equation the variable DeltaGDPgap is instrumented by the variable InvestS1990. The correlation coefficient of these two measures is rho $=-0.2766 \mathrm{p}$-value $=0.0148$. In the second equation the variable DeltaMig is instrumented by the variable Mig1990. The correlation coefficient of these two measures is rho= $0.3715 \mathrm{p}$-value $=0.0008$. In the second Hausman test, under the alternative hypothesis the 2SLS estimator is consistent but the 3SLS estimator is inconsistent. 
Figure 1

Migration in equilibrium for given public investment
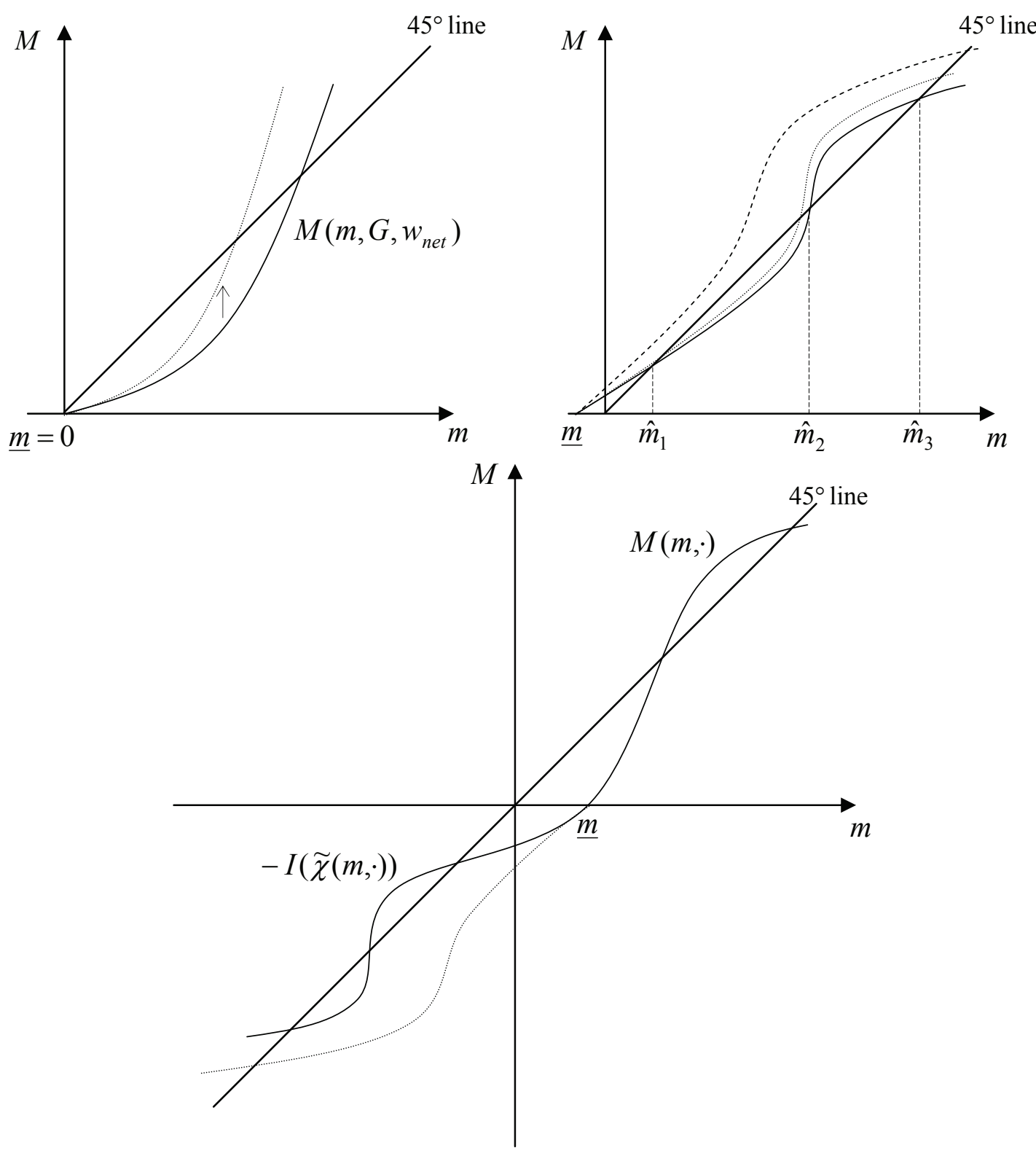
Figure 2

Welfare as a function of $G$ for a given migration flow, $m_{2}>m_{1}$

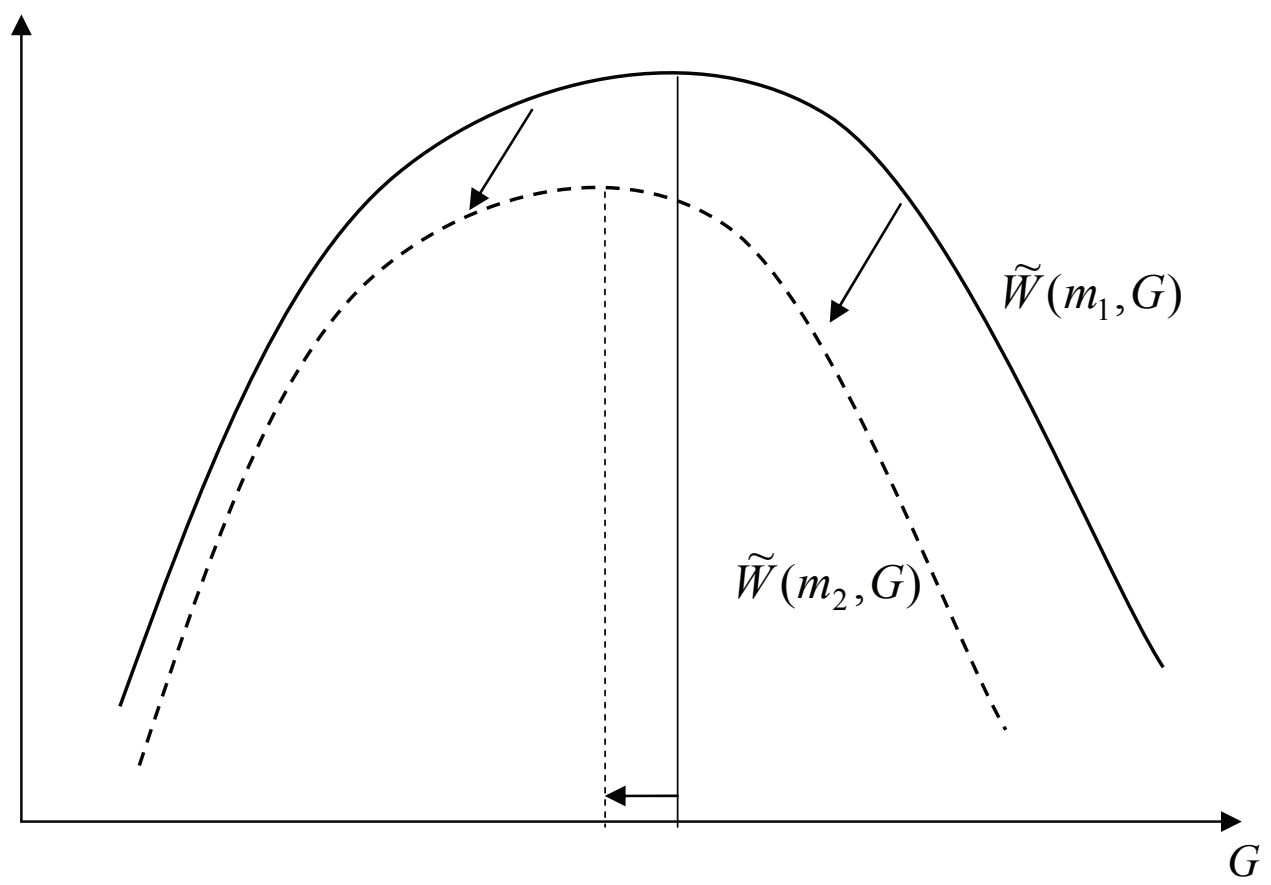


Figure 3

Correlation between changes in income gaps and changes in emigration rates

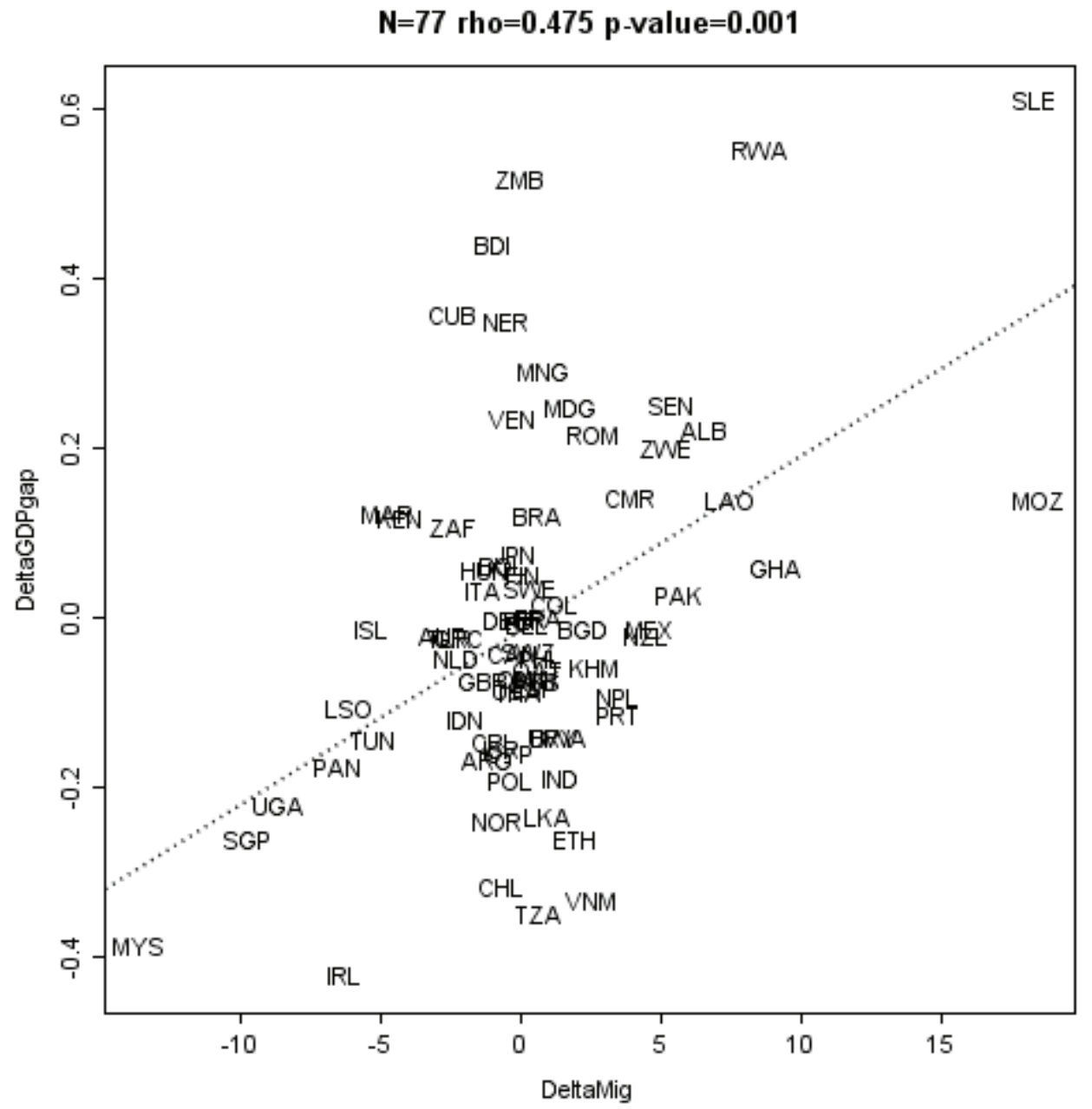

Notes: rho represents the Spearman correlation coefficient. The p-value results from a test of the significance of the correlation. 
Figure 4

Correlation between changes in public investment levels (as fraction of GDP) and changes in emigration rates
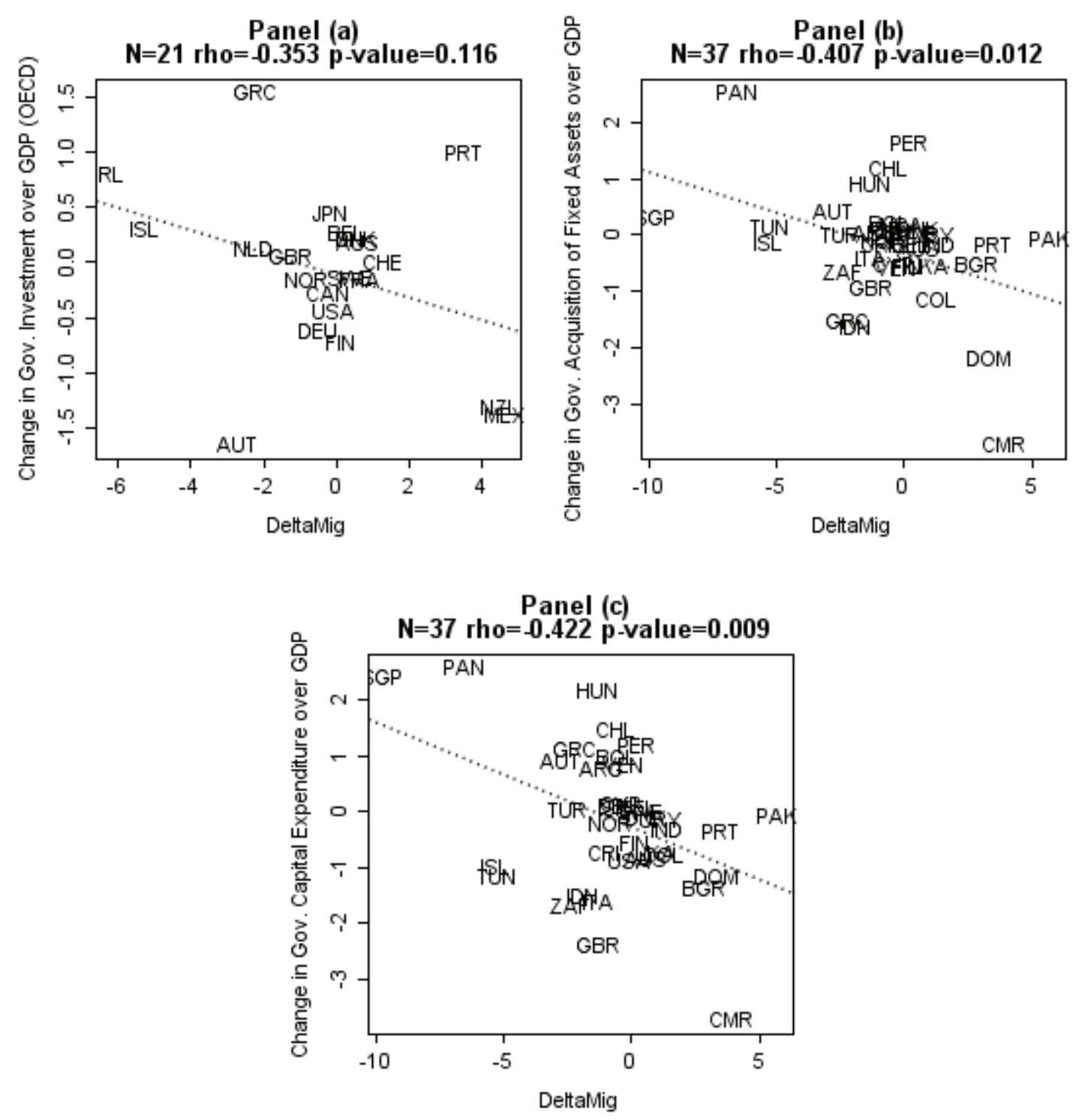

Notes: rho represents the Spearman correlation coefficient. The p-value results from a test of the significance of the correlation. The government investment data for the first plot comes from the OECD databases. Government investment data for the other two plots was obtained from the IMF Government Financial Statistics from 1990 to 1992 and 1999 to 2001 (missing data matched with nearest year). 